\title{
Mixed-Salt Enhanced Chemical Vapor Deposition of Two-Dimensional Transition
}

\section{Metal Dichalcogenides}

Shisheng Li, ${ }^{* 1}$ Yung-Chang Lin, ${ }^{2}$ Jinhua Hong, ${ }^{2}$ Bo Gao, ${ }^{3,4}$ Hong En Lim, ${ }^{5}$ Xu Yang, ${ }^{6}$ Song

Liu, ${ }^{7}$ Yoshitaka Tateyama, ${ }^{3,4}$ Kazuhito Tsukagoshi, ${ }^{3}$ Yoshiki Sakuma, ${ }^{6}$ Kazu Suenaga, ${ }^{2,8}$ and Takaaki Taniguchi*3

1 International Center for Young Scientists (ICYS), National Institute for Materials Science (NIMS), Tsukuba 305-0044, Japan

2 Nanomaterials Research Institute, National Institute of Advanced Industrial Science and Technology, AIST Central 5, Tsukuba 305-8565, Japan

3 International Center for Materials Nanoarchitectonics (WPI-MANA), National Institute for Materials Science (NIMS), Tsukuba 305-0044, Japan

4 Center for Green Research on Energy and Environmental Materials (GREEN), National Institute for Materials Science (NIMS), Tsukuba 305-0044, Japan

5 Department of Physics, Tokyo Metropolitan University, Hachioji 192-0397, Japan

6 Research Center for Functional Materials, National Institute for Materials Science (NIMS), Tsukuba 305-0044, Japan

7 Institute of Chemical Biology and Nanomedicine (ICBN), College of Chemistry and Chemical Engineering, Hunan University, Changsha 410082, P. R. China

8 The Institute of Scientific and Industrial Research (ISIR-SANKEN), Osaka University, Osaka 567-0047, Japan 


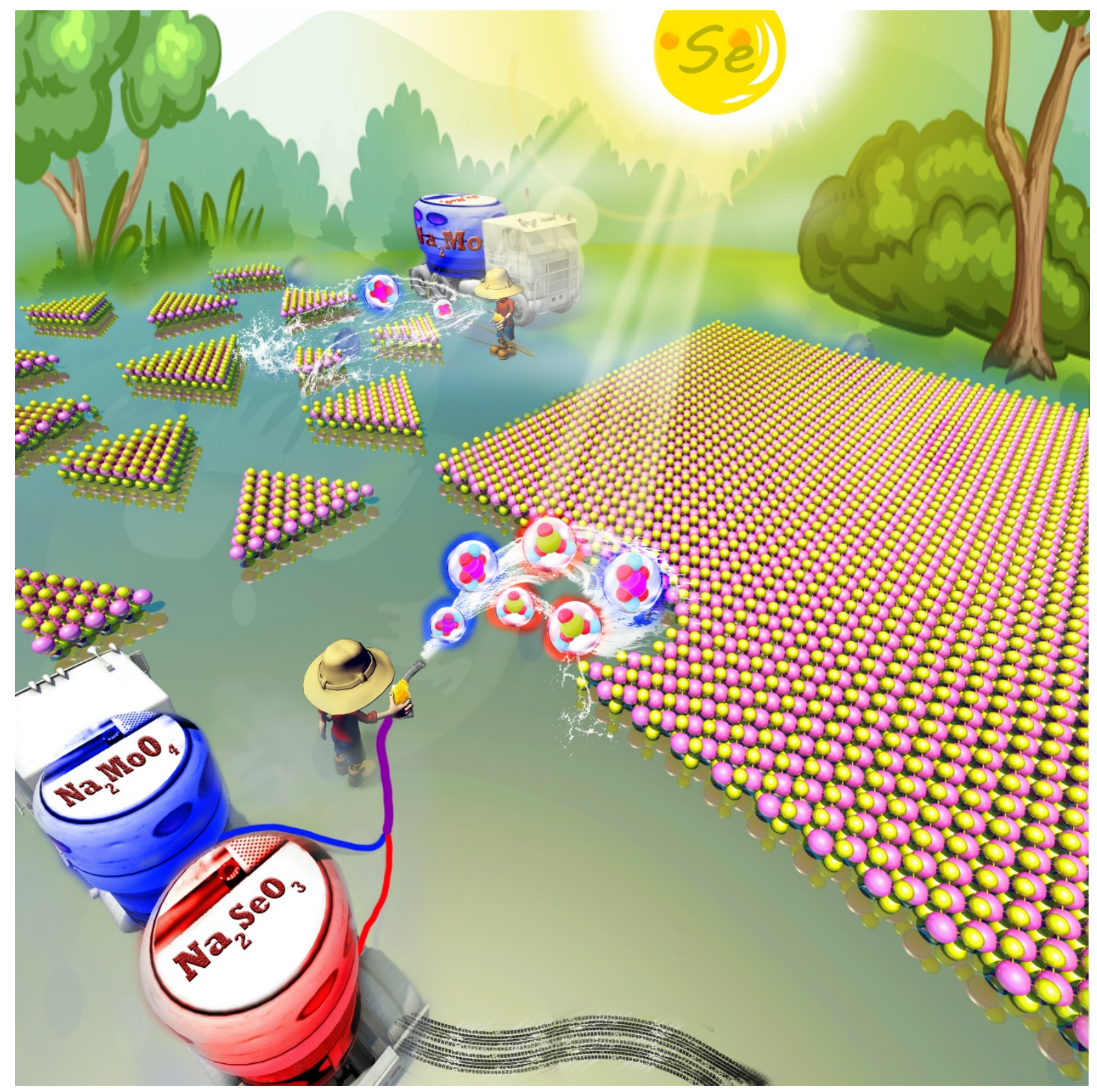

Boosting growth of $\mathrm{MoSe}_{2}$ with $\mathrm{Na}_{2} \mathrm{SeO}_{3}$. An enhanced CVD growth of continuous $\mathrm{MoSe}_{2}$ film was achieved by adding $\mathrm{Na}_{2} \mathrm{SeO}_{3}$ to $\mathrm{Na}_{2} \mathrm{MoO}_{4}$. This work provides a general strategy for large-area growth of 2D transition metal dichalcogenides using mixed molten salts. 


\section{Abstract}

The usage of molten salts, e.g., $\mathrm{Na}_{2} \mathrm{MoO}_{4}$ and $\mathrm{Na}_{2} \mathrm{WO}_{4}$, has shown great success in the growth of two-dimensional (2D) transition metal dichalcogenides (TMDCs) by chemical vapor deposition (CVD). In comparison with the halide salt (i.e., $\mathrm{NaCl}, \mathrm{NaBr}, \mathrm{KI}$ )-assisted growth (Salt 1.0), the molten salt-assisted vapor-liquid-solid (VLS) growth technique (Salt 2.0) has improved the reproducibility, efficiency and scalability of synthesizing 2D TMDCs. However, the growth of large-area $\mathrm{MoSe}_{2}$ and $\mathrm{WTe}_{2}$ is still quite challenging with the use Salt 2.0 technique. In this study, a renewed Salt 2.0 technique using mixed salts (e.g., $\mathrm{Na}_{2} \mathrm{MoO}_{4}$ $\mathrm{Na}_{2} \mathrm{SeO}_{3}$ and $\mathrm{Na}_{2} \mathrm{WO}_{4}-\mathrm{Na}_{2} \mathrm{TeO}_{3}$ ) is developed for the enhanced CVD growth of $2 \mathrm{D} \mathrm{MoSe}_{2}$ and $\mathrm{WTe}_{2}$ crystals with large grain size and yield. Continuous monolayer $\mathrm{MoSe}_{2}$ film with grain size of $100-250 \mu \mathrm{m}$ or isolated flakes up to $\sim 450 \mu \mathrm{m}$ is grown on a halved 2-inch $\mathrm{SiO}_{2} / \mathrm{Si}$ wafer. Our study further confirms the synergistic effect of $\mathrm{Na}^{+}$and $\mathrm{SeO}_{3}{ }^{2-}$ in the enhanced CVD growth of wafer-scale monolayer $\mathrm{MoSe}_{2}$ film. And thus, the addition of $\mathrm{Na}_{2} \mathrm{SeO}_{3}$ and $\mathrm{Na}_{2} \mathrm{TeO}_{3}$ into the transition metal salts could be a general strategy for the enhanced CVD growth of many other 2D selenides and tellurides.

\section{INTRODUCTION}

Two-dimensional (2D) layered transition-metal dichalcogenides (TMDCs) with unique electrical properties are promising materials for future electronic devices. Among them, the semiconducting TMDCs (e.g., $\mathrm{MoS}_{2}, \mathrm{MoSe}_{2}, \mathrm{WSe} 2$, etc.) are idea channel materials for field effect transistors (FETs) because of their high carrier mobility and current on/off ratio, which may reach from tens to hundreds $\mathrm{cm}^{2} /$ Vs and up to $10^{8}$, respectively. ${ }^{1-3}$ Meanwhile, the metallic 
TMDCs (e.g., $\mathrm{VSe}_{2}, \mathrm{VTe}_{2}, \mathrm{WTe}_{2}$, etc. $)^{4-7}$ also play important roles in future all-2D integrated circuits as contacts and interconnects. ${ }^{8}$ To realize their potential application in 2D electronics, the TMDCs should be prepared with high crystallinity, uniformity and reproducibility at low cost.

In the past decade, many growth techniques were employed for the synthesis of $2 \mathrm{D}$ TMDCs, from chemical vapor transport (CVT) growth of bulk TMDC crystals to the pioneering chemical vapor deposition (CVD) growth of $\mathrm{MoS}_{2}$, and then metal organic (MO) CVD synthesis of large-area 2D TMDCs. ${ }^{9-12}$ Among these approaches, CVD is the most promising method due to its low cost, easy controllability, and scalability for mass production. The typical CVD growth of 2D TMDCs usually involves the powders of transition metal oxides and chalcogen precursors, where the 2D TMDCs are grown via a vapor-solid-solid (VSS) growth mechanism. However, some oxides (e.g., $\mathrm{WO}_{3}$ and $\mathrm{Nb}_{2} \mathrm{O}_{5}$ ) with high melting points close to $1500{ }^{\circ} \mathrm{C}$ are hard to vaporize at the common growth temperature of $700-900{ }^{\circ} \mathrm{C} .{ }^{13}$ To solve this issue, we first introduced halides (e.g., $\mathrm{NaCl}, \mathrm{NaBr}, \mathrm{KI}$, etc.) as growth promoters to facilitate the growth of large $\mathrm{WS}_{2}$ and $\mathrm{WSe}_{2}$ monolayers. ${ }^{14}$ Such improved CVD growth is attributed to the in-situ generated oxyhalides, which have low melting points around $300{ }^{\circ} \mathrm{C}$ and thus providing sufficient high vapor pressure for the feasible growth of 2D TMDCs. This Salt 1.0 technique had succeeded in growing tens different kinds of layered metal chalcogenides and their alloys/junctions. ${ }^{15}$ A recent study found that the fluoride can also facilitate the growth of graphene and h-BN monolayers. ${ }^{16}$ However, the Salt 1.0 technique following the VSS growth mechanism has several intrinsic drawbacks, which include nonuniform metal precursor (vapor) distribution on the growth substrate, poor coverage uniformity 
and reproducibility, and contamination on growth chambers. These cause the wafer-scale and patterned growth of TMDCs almost impossible. Furthermore, extra costs are needed to replace the contaminated growth chambers/tubes frequently.

Until recently, Salt 2.0 technique has been developed to enable the CVD growth of 1D and 2D TMDCs via a vapor-liquid-solid (VLS) mechanism. ${ }^{17-20}$ This method uses the molten salts, e.g., $\mathrm{Na}_{2} \mathrm{Mo}_{2} \mathrm{O}_{7}, \mathrm{Na}_{2} \mathrm{MoO}_{4}, \mathrm{Na}_{2} \mathrm{WO}_{4}, \mathrm{NaReO}_{4}, \mathrm{NaVO}_{3}$, etc., which have melting points close to the typical TMDC growth temperatures $\left(650-850{ }^{\circ} \mathrm{C}\right)$. During the reaction, these transition metal salts are in molten liquid state, which is essentially different from those in the Salt 1.0 technique. The molten salts have the advantage to be prepared in stable aqueous solutions that can either be uniformly deposited on large wafers via spin-coating or to form patterns on substrates. We had indeed demonstrated 2-inch wafer-scale and deterministic patterned growth of $\mathrm{MoS}_{2}$ and $\mathrm{WS}_{2}$ monolayers using $\mathrm{Na}_{2} \mathrm{MoO}_{4}$ and $\mathrm{Na}_{2} \mathrm{WO}_{4}$ aqueous solutions, respectively. ${ }^{18,19}$ Zuo et al., also demonstrated the growth of $\mathrm{MoS}_{2}, \mathrm{MoSe}_{2}, \mathrm{WS}_{2}$ and $\mathrm{WSe}_{2}$ inside the channels of optical fibers using the Salt 2.0 technique, resulting in an ultrahigh nonlinearity ever achieved. ${ }^{21}$ In addition, we also demonstrated the CVD growth of rhenium (Re) and vanadium (V)-doped TMDCs by simply mixing molten salt aqueous solutions in designated ratios. These CVD-grown Re- and V-doped TMDCs with tunable dopants concentrations, electrical and optical properties are highly promising for future electronic and optoelectronics. $^{22}$ The Salt 2.0 technique is hence, highly promising towards the practical application of 2D TMDC-based electronics.

In this paper, we report an enhanced CVD growth of $2 \mathrm{D} \mathrm{MoSe}_{2}, \mathrm{ReSe}_{2}$ and $\mathrm{WTe}_{2}$, which are still quite challenging to grow with the Salt 2.0 technique using $\mathrm{Na}_{2} \mathrm{MoO}_{4}, \mathrm{NaReO}_{4}$, and 
$\mathrm{Na}_{2} \mathrm{WO}_{4}$ only. By using mixed transition metal salts and halogen salts, e.g., $\mathrm{Na}_{2} \mathrm{MoO}_{4}-\mathrm{Na}_{2} \mathrm{SeO}_{3}$, $\mathrm{NaReO}_{4}-\mathrm{Na}_{2} \mathrm{SeO}_{3}$ and $\mathrm{Na}_{2} \mathrm{WO}_{4}-\mathrm{Na}_{2} \mathrm{TeO}_{3}$, much improved growth of $\mathrm{MoSe}_{2}, \mathrm{ReSe}_{2}$ and $\mathrm{WTe}_{2}$ is achieved, respectively. The most substantial achievement lies in the growth of continuous $\mathrm{MoSe}_{2}$ film on a halved 2-inch $\mathrm{SiO}_{2} / \mathrm{Si}$ wafer with large grain sizes of $100-250 \mu \mathrm{m}$ or isolated flakes up to $\sim 450 \mu \mathrm{m}$ using the $\mathrm{Na}_{2} \mathrm{MoO}_{4}-\mathrm{Na}_{2} \mathrm{SeO}_{3}$, which is much better than that grown using $\mathrm{Na}_{2} \mathrm{MoO}_{4}$ only. Similarly, the $\mathrm{ReSe}_{2}$ and $\mathrm{WTe}_{2}$ also show much improved yield and grain size with the addition of $\mathrm{Na}_{2} \mathrm{SeO}_{3}$ and $\mathrm{Na}_{2} \mathrm{TeO}_{3}$, respectively. Our theoretical studies indicate that the growth of 2D Se- and Te-based TMDCs is thermodynamically favored when the chalcogen salts are introduced. The chalcogen salts added can effectively decrease the formation energies of 2D TMDCs. Such enhanced CVD growth using mixed salts strategy therefore provides a robust synthetic alternative for many 2D selenides and tellurides towards future electronics.

\section{RESULTS AND DISSCUSSIONS}

\section{Strategy for enhanced CVD growth of 2D TMDCs using mixed salt precursors}

The successful growth of 2D TMDCs with the Salt 2.0 technique requires a careful choice of salt precursors. Basically, the molten salts need to meet two main criteria: 1) possess reasonably high melting points; 2) formation of stable aqueous solutions, considering the growth mechanism involved. Take the VLS growth of 1D $\mathrm{MoS}_{2}$ nanoribbons for instance, molten Na-Mo-O salt $\left(\mathrm{Na}_{2} \mathrm{Mo}_{2} \mathrm{O}_{7}\right)$ first forms liquid droplets on the growth substrates. Then, the sulfur vapor adsorbs on their surface and diffuses into the droplets, forming Na-Mo-S-O. When the Na-Mo-O-S droplets become supersaturated with sulfur, solid $\mathrm{MoS}_{2}$ nanoribbons are 
precipitated out finally. ${ }^{17}$ And thus, precursors with a suitable range of heat tolerance/stability and easy incorporation of chalcogen are crucial to initiate seeding and to mediate growth.

Figure 1a shows some transition metal salts that have been used for the successful growth of 2D transition metal sulfide. ${ }^{17,21,23}$ However, it is still quite challenging to grow large-area, high-quality 2D transition metal selenide (e.g., $\mathrm{MoSe}_{2}$ ) and tellurides (e.g., $\mathrm{WTe}_{2}$ ) using these precursors. We attribute this to the difficult incorporation of chalcogen atoms, especially Se and Te in the transition metal salts to initiate the TMDC nucleation and the subsequent growth. In previous study, tellurium was mixed with $\mathrm{MoO}_{3}$, tungsten and rhenium to promote the growth $2 \mathrm{D}$ transition metal sulfides, $\mathrm{MoS}_{2}, \mathrm{WS}_{2}$ and $\mathrm{ReS}_{2}$, respectively. ${ }^{24,25}$ To overcome this, chalcogen salts, e.g., $\mathrm{Na}_{2} \mathrm{SeO}_{3}$ and $\mathrm{Na}_{2} \mathrm{TeO}_{3}$ with similar chemical properties (reasonably high melting points and soluble in $\mathrm{H}_{2} \mathrm{O}$ ) were added to the transition metal salts to prepare the mixed-salt aqueous solutions. Compared to the molten salts with Na-Mo-O or Na-W-O only, the mixed molten salts containing Na-Mo-Se-O or Na-W-Te-O may assist the nucleation during the temperature ramping process and facilitate the rapid growth of 2D TMDCs when elemental chalcogen vapor is introduced at the growth stage. To confirm this idea, we first prepared the mixed-salt aqueous solutions. Then, the solutions were spin-coated onto the growth substrates. CVD growth was performed in a 2-inch tube furnace with Se or Te powder loaded in the upstream and growth substrates positioned at the center. The synthetic strategy and method are illustrated in Figure $1 \mathrm{~b}$ and Figure S1. 

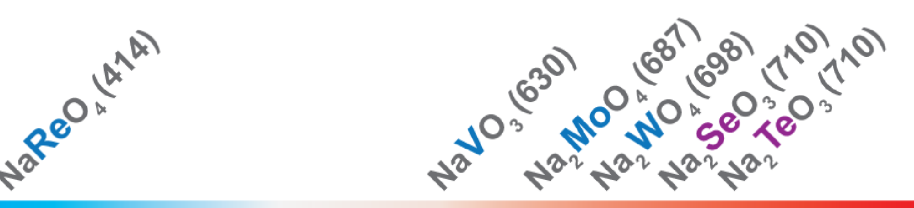

Melting points $\left({ }^{\circ} \mathrm{C}\right)$

CVD temp. $650-850^{\circ} \mathrm{C}$

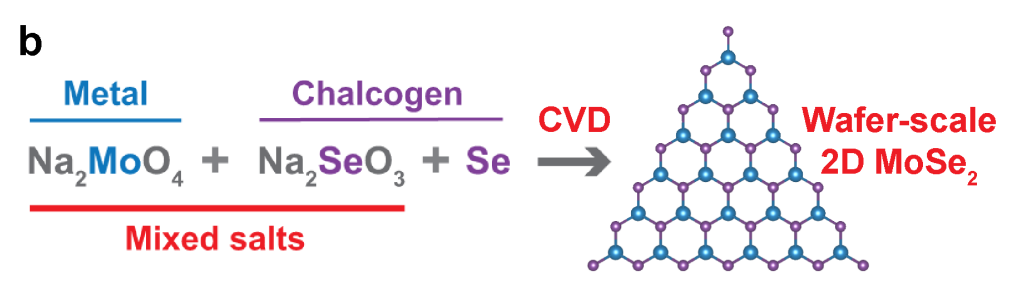

Figure 1. Enhanced CVD growth of 2D TMDCs with mixed transition metal salts and chalcogen salts. (a) A color bar indicating the melting points of several salt precursors. (b) The synthetic strategy for enhanced CVD growth of wafer-scale 2D $\mathrm{MoSe}_{2}$ films with mixed-salt precursors.

\section{Enhanced CVD growth of $\mathrm{MoSe}_{2}$ monolayers using mixed $\mathrm{Na}_{2} \mathrm{MoO}_{4}-\mathrm{Na}_{2} \mathrm{SeO}_{3}$}

To evaluate the proposed strategy for enhanced CVD, we first conducted the growth of $\mathrm{MoSe}_{2}$ monolayers using the mixed $\mathrm{Na}_{2} \mathrm{MoO}_{4}-\mathrm{Na}_{2} \mathrm{SeO}_{3}(16 \mathrm{mM}, 1: 1)$ solution. Figure $2 \mathrm{a}$ is a photo showing a uniform $\mathrm{MoSe}_{2}$ film grown on a halved 2-inch $\mathrm{SiO}_{2} / \mathrm{Si}$ wafer, which has an obvious color contrast different from the bare $\mathrm{SiO}_{2} / \mathrm{Si}$ wafer. Low-magnification optical image shows that the $\mathrm{MoSe}_{2}$ film grown with $\mathrm{Na}_{2} \mathrm{MoO}_{4}-\mathrm{Na}_{2} \mathrm{SeO}_{3}$ has a full coverage with a fairly low-density of thick-layers (Figure 2b). Our statistical result indicates a high coverage yield of $\mathrm{MoSe}_{2}$ monolayer up to $\sim 98.3 \%$. A fine control of the mixed salts' concentrations is anticipated to result in a full coverage of $\mathrm{MoSe}_{2}$ monolayer in future. High-magnification optical images reveal that the as-grown $\mathrm{MoSe}_{2}$ monolayer has large domain size in the range of 100-250 $\mu \mathrm{m}$ (Figure 2c, Figure S2a and S2b). When the $\mathrm{Na}_{2} \mathrm{MoO}_{4}: \mathrm{Na}_{2} \mathrm{SeO}_{3}$ molar ratio 
changes to $1: 2$, large $\mathrm{MoSe}_{2}$ monolayers with a domain size up to $\sim 450 \mu \mathrm{m}$ are observed (Figure S2c). Meanwhile in the controlled growth without adding any $\mathrm{Na}_{2} \mathrm{SeO}_{3}$, only small $(\sim 10 \mu \mathrm{m})$ $\mathrm{MoSe}_{2}$ flakes are grown (Figure 2d and Figure S2d).

Figure 2e is a typical Raman spectrum of as-grown monolayer $\mathrm{MoSe}_{2}$ film with the characteristic $\mathrm{A}_{1 \mathrm{~g}}$ peak located at $239.8 \mathrm{~cm}^{-1}$, which is slightly higher than the strain-free exfoliated $\mathrm{MoSe}_{2}$ monolayers, $\sim 239.5 \mathrm{~cm}^{-1} \cdot{ }^{26}$ Figure $2 \mathrm{f}$ shows an optical image and corresponding Raman maps of two adjacent monolayer $\mathrm{MoSe}_{2}$ domains. The Raman peak position map over a large area of $165 \times 355 \mu \mathrm{m}^{2}$ demonstrates a small variation from 238.9 to $239.8 \mathrm{~cm}^{-1}$. We attribute the Raman peak variation to the strain existed in the CVD-grown monolayer $\mathrm{MoSe}_{2}$ film. ${ }^{27,}{ }^{28}$ Nonetheless, the Raman peak intensity map shows a good uniformity. The intensity gradient from the bottom left to top right is attributable to the different focusing conditions encountered in such a large mapping area caused by the uneven substrate/sample stage. Figure $2 \mathrm{~g}$ is a typical photoluminescence (PL) spectrum of as-grown monolayer $\mathrm{MoSe}_{2}$ with a peak position located at $\sim 837 \mathrm{~nm}(\sim 1.481 \mathrm{eV})$ corresponding to the A exciton emission. The small FWHM of $\sim 40 \mathrm{meV}$ indicates a good optical quality of asgrown monolayer $\mathrm{MoSe}_{2}$ film. ${ }^{26,29-31}$ Figure $2 \mathrm{~h}$ shows an optical image and corresponding PL maps of two adjacent monolayer $\mathrm{MoSe}_{2}$ domains. In the large mapping area of $120 \times 300 \mu \mathrm{m}^{2}$, the PL maps demonstrate small deviation in peak position (photon energy) and peak intensity, indicating a great optical uniformity in such large monolayer $\mathrm{MoSe}_{2}$ domains. $^{29,30}$

The structural analysis performed on the transferred $\mathrm{MoSe}_{2}$ monolayer via annular dark-field (ADF) scanning transmission electron microscopy (STEM) reveals that the $\mathrm{MoSe}_{2}$ monolayer has a good crystallinity (Figure 2i). A small portion of Se vacancies is observed, possibly due 
to the hydrogen etching occurred during the cooling process. We further investigated the electrical quality of the as-grown $\mathrm{MoSe}_{2}$ monolayers by fabricating FETs (Figure S3a-c). The $\mathrm{MoSe}_{2}$-FETs show typical n-type transport behavior with a high current on/off ratio up to $10^{8}$ (Figure $2 \mathrm{j}$ ). From a total 16 devices measured, they show current on/off ratios around $10^{8}-10^{9}$ and electron mobilities range from 5.2 to $16.4 \mathrm{~cm}^{2} / \mathrm{Vs}$ with an average of $8.2 \mathrm{~cm}^{2} / \mathrm{Vs}$ (Figure S3d). It is noteworthy to mention that the electrical performance of our CVD-grown monolayer $\mathrm{MoSe}_{2}$ film is similar or to a certain extent better than the previously reported, CVD-grown isolated flakes and continuous film. ${ }^{32-37}$ Although high-mobility monolayer $\mathrm{MoSe}_{2}$ have also been grown by Wang et al. and Li et. al., ${ }^{29,38}$ they are limited only to isolated submillimetresize flakes. It is therefore crucial to seek a feasible growth that accommodates large-area growth of high-quality $\mathrm{MoSe}_{2}$ film. Furthermore, the value obtained is still incomparable to that of the CVD-grown $\mathrm{MoS}_{2}$ monolayers, ${ }^{18,} 39$ the electrical performance, environmental stability and crystallinity of our CVD-grown monolayer $\mathrm{MoSe}_{2}$ films can be further improved by using a fast-cooling process with high-flux of Se vapor. ${ }^{40}$ Notably, enhanced CVD growth of $2 \mathrm{D} \mathrm{ReSe} \mathrm{R}_{2}$ flakes is also achieved via the use of mixed $\mathrm{NaReO}_{4}-\mathrm{Na}_{2} \mathrm{SeO}_{3}$ (Figure S4). It could be a versatile strategy for growing many other 2D metal selenides. 
a
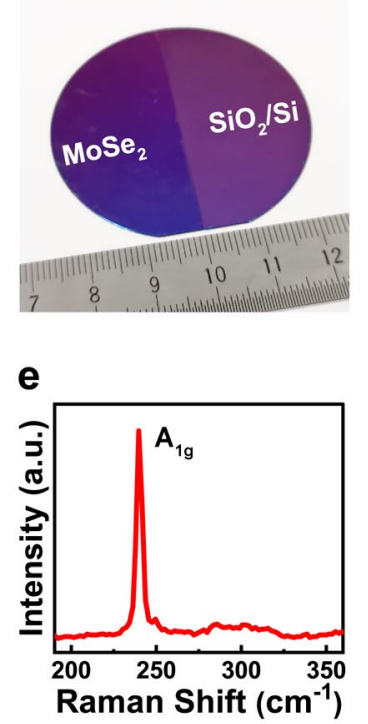

b
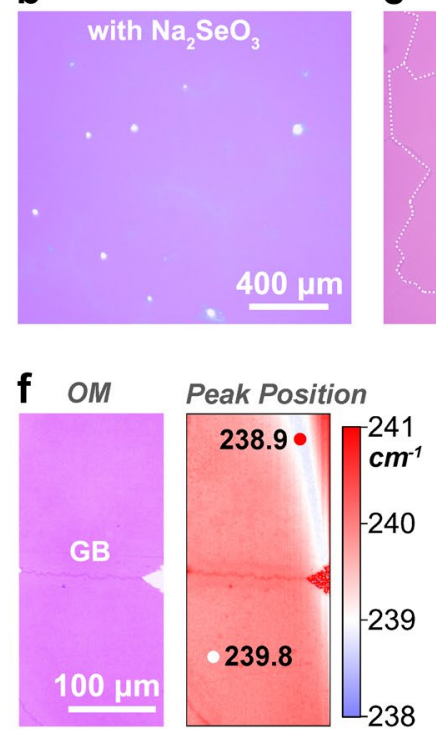

i
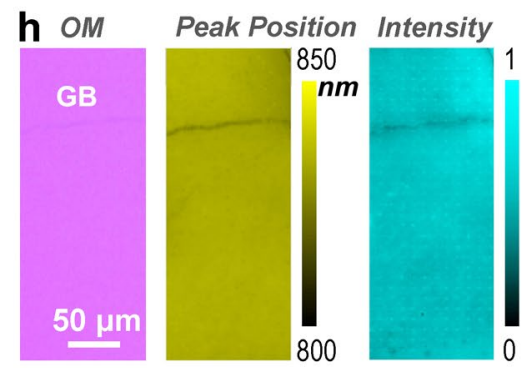

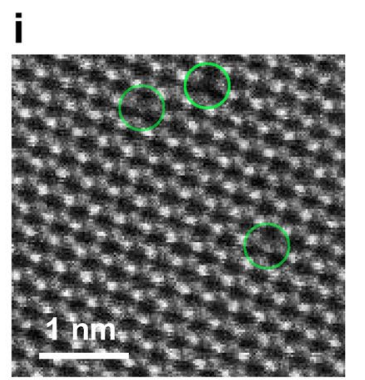

C
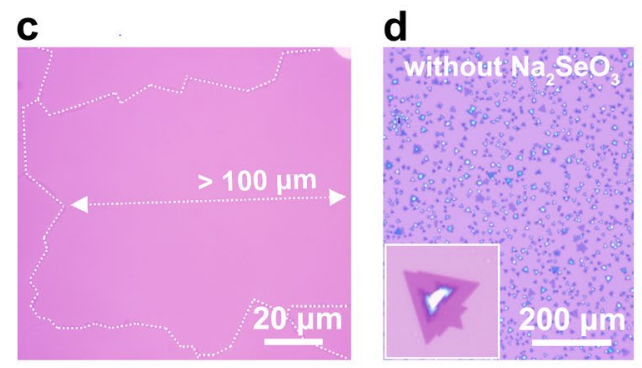

Intensity
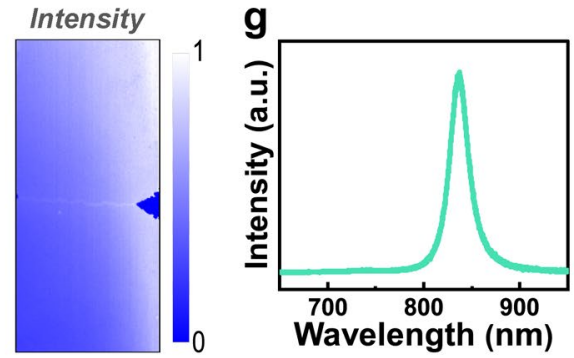

j

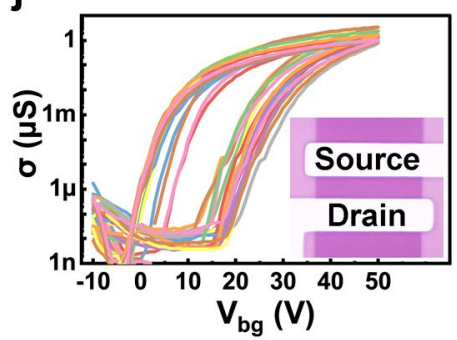

Figure 2. Characterization of $\mathrm{MoSe}_{2}$ monolayers grown with $\mathrm{Na}_{2} \mathrm{MoO}_{4}-\mathrm{Na}_{2} \mathrm{SeO}_{3}$. (a) A photo of monolayer $\mathrm{MoSe}_{2}$ film grown on a halved 2-inch wafer. (b, c) Optical images of monolayer $\mathrm{MoSe}_{2}$ film grown with the mixed salts. The dotted lines indicate the grain boundaries (GB). (d) An optical image of $\mathrm{MoSe}_{2}$ grown with $\mathrm{Na}_{2} \mathrm{MoO}_{4}$ only. Inset shows a typical $\mathrm{MoSe}_{2}$ flake in an area of $10 \times 10 \mu \mathrm{m}^{2}$. (e) Typical Raman spectrum of the as-grown $\mathrm{MoSe}_{2}$ monolayer. (f) OM image and corresponding Raman peak position and intensity maps. (g) Typical PL spectrum of the as-grown $\mathrm{MoSe}_{2}$ monolayer. (h) OM image and corresponding PL peak position and intensity maps. (i) A typical ADF-STEM image of the as-grown $\mathrm{MoSe}_{2}$ monolayer. The green circles indicate the single and double Se vacancies in the $\mathrm{MoSe}_{2}$ lattice. (j) Transport curves of $\mathrm{MoSe}_{2}$-FETs. Inset shows the channel area of a MoSe 2 -FET. The data presented in figures e-j were obtained from monolayer $\mathrm{MoSe}_{2}$ films grown with the mixed salts. 


\section{Enhanced CVD growth of WTe $\mathrm{W}_{2}$ using mixed $\mathrm{Na}_{2} \mathrm{WO}_{4}-\mathrm{Na}_{2} \mathrm{TeO}_{3}$}

We further evaluated the CVD growth of $\mathrm{WTe}_{2}$ using mixed $\mathrm{Na}_{2} \mathrm{WO}_{4}-\mathrm{Na}_{2} \mathrm{TeO}_{3}$ and $\mathrm{Na}_{2} \mathrm{WO}_{4}$ only. Figure $3 \mathrm{a}$ and $3 \mathrm{~b}$ are optical images of few-layer $\mathrm{WTe} \mathrm{e}_{2}$ flakes grown on sapphire substrate with $\mathrm{Na}_{2} \mathrm{WO}_{4}-\mathrm{Na}_{2} \mathrm{TeO}_{3}(30 \mathrm{mM}, 1: 1)$. In contrast to the thick, small flakes grown (Figure $3 \mathrm{c}$ and inset), addition of the $\mathrm{Na}_{2} \mathrm{TeO}_{3}$ results in the growth of thin $\mathrm{WTe}_{2}$ of much larger size (Figure $3 \mathrm{a}$ and $3 \mathrm{~b}$ ). Figure $3 \mathrm{~d}$ is an atomic force microscope (AFM) image obtained from a $\mathrm{WTe}_{2}$ flake grown with the mixed salts. Most of the $\mathrm{WTe}_{2}$ flakes have a height of $\sim 2.1 \mathrm{~nm}$, corresponding to a tri-layer structure (Figure 3d). A typical Raman spectrum of as-grown WTe 2 flake on sapphire substrate is presented in Figure 3e. Five characteristic peaks located at 110.7 $\mathrm{cm}^{-1}, 116.6 \mathrm{~cm}^{-1}, 134.0 \mathrm{~cm}^{-1}, 163.0 \mathrm{~cm}^{-1}$, and $211 \mathrm{~cm}^{-1}$ are well-matched to the Raman active modes $\left(A_{2}^{4}, A_{1}^{3}, A_{1}^{5}, A_{1}^{7}, A_{1}^{9}\right)$ of $\mathrm{T}^{\prime}-\mathrm{WTe}_{2} \cdot{ }^{41}$ Figure 3 f shows a typical high-resolution ADF-STEM image and the atomic structure of $\mathrm{T}^{\prime}-\mathrm{WTe}_{2}$. The typical transport curve of a tri-layer $\mathrm{WTe}_{2}-$ FET in Figure $3 \mathrm{~g}$ shows good metallic transport behaviour with poor gate dependency and high conductivity. It could be a promising contact material for future $2 \mathrm{D}$ electronics. ${ }^{6,7}$ 

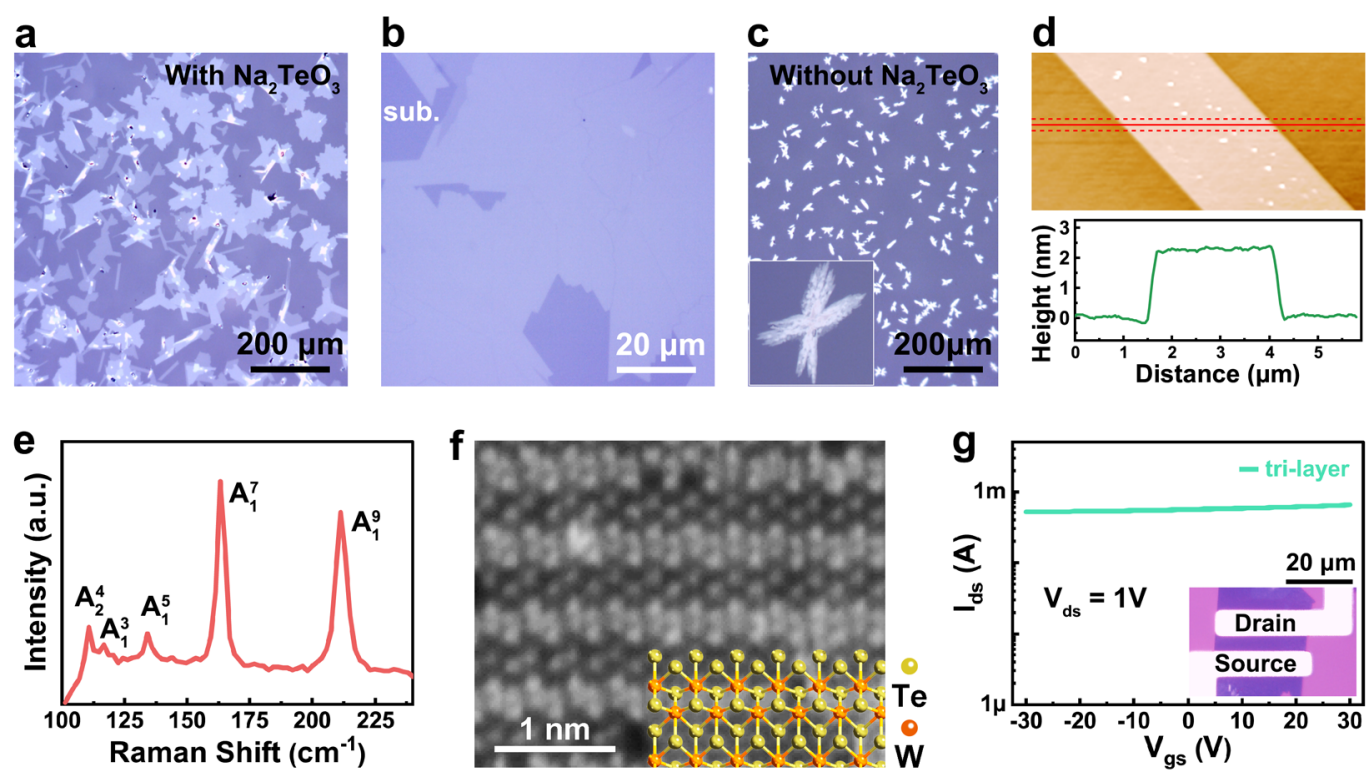

Figure 3. Characterization of the $\mathrm{WTe}_{2}$ grown with $\mathrm{Na}_{2} \mathrm{WO}_{4}-\mathrm{Na}_{2} \mathrm{TeO}_{3}$. (a, b) Optical images of few-layer $\mathrm{WTe}_{2}$ grown with the mixed $\mathrm{Na}_{2} \mathrm{WO}_{4}-\mathrm{Na}_{2} \mathrm{TeO}_{3}$. (c) An optical image of the $\mathrm{WTe}_{2}$ grown with $\mathrm{Na}_{2} \mathrm{WO}_{4}$ only. Inset shows a single $\mathrm{WTe}_{2}$ flake in an area of $10 \times 10 \mu \mathrm{m}^{2}$. (d) AFM image and height profile of a WTe 2 flake. (e) Raman spectra of as-grown $\mathrm{T}^{\prime}-\mathrm{WTe} \mathrm{e}_{2}$.

(f) Typical ADF-STEM image and atomic models of as-grown $\mathrm{T}^{\prime}-\mathrm{WTe} \mathrm{e}_{2}$. (g) Typical transport curve of a tri-layer $\mathrm{WTe}_{2}-\mathrm{FET}$. Inset shows the optical image of the channel area. Data in figure d-g were obtained from the $\mathrm{WTe}_{2}$ flakes grown with the mixed salts.

\section{The mechanism for improved CVD growth of 2D TMDCs with mixed salts}

To reveal the mechanism for such enhanced CVD growth using mixed salts, we compared the $\mathrm{MoSe}_{2}$ growth in separate sets of experiments to identify the functions of $\mathrm{SeO}_{3}{ }^{2-}$ and $\mathrm{Na}^{+}$, respectively.

First, we clarify the effectiveness of $\mathrm{SeO}_{3}{ }^{2-}$ by using salt precursors without/with $\mathrm{SeO}_{3}{ }^{2-}$ at fixed $\mathrm{Na}^{+}$and $\mathrm{MoO}_{4}{ }^{2-}$ molar ratio, i.e. $\mathrm{Na}_{2} \mathrm{MoO}_{4}(16 \mathrm{mM})$ and $\left(\mathrm{NH}_{4}\right)_{2} \mathrm{MoO}_{4}-\mathrm{Na}_{2} \mathrm{SeO}_{3}(16 \mathrm{mM}$, 
1:1). Figure 4 a shows a halved 2-inch $\mathrm{SiO}_{2} / \mathrm{Si}$ wafer fully covered with a uniform $\mathrm{MoSe}_{2}$ film grown with $\left(\mathrm{NH}_{4}\right)_{2} \mathrm{MoO}_{4}-\mathrm{Na}_{2} \mathrm{SeO}_{3}$, where $\mathrm{Na}^{+}: \mathrm{MoO}_{4}{ }^{2-}: \mathrm{SeO}_{3}{ }^{2-}=2: 1: 1$. Optical images show that the as-grown $\mathrm{MoSe}_{2}$ film comprises mainly of continuous monolayers with small portion of voids and thick layers (Figure $4 \mathrm{~b}$ and $4 \mathrm{c}$ ). The as-grown $\mathrm{MoSe}_{2}$ film also shows uniform Raman (Figure 4d) and PL spectra (Figure 4e) over the whole wafer. Furthermore, this mixed salts also demonstrate high growth reproducibility (Figure S5a-c). Compared to the growth using $\mathrm{Na}_{2} \mathrm{MoO}_{4}$ only with the same $\mathrm{Na}^{+}: \mathrm{MoO}_{4}{ }^{2-}$ molar ratio of $2: 1$ (Figure $2 \mathrm{~d}$ ), the addition of $\mathrm{SeO}_{3}{ }^{2-}$ can effectively improve the growth of $\mathrm{MoSe}_{2}$ monolayers. This further confirms the effectiveness of chalcogen salts in the enhanced CVD growth of 2D TMDCs. It is important to mention that the enhanced $\mathrm{MoSe}_{2}$ growth using $\left(\mathrm{NH}_{4}\right)_{2} \mathrm{MoO}_{4}-\mathrm{Na}_{2} \mathrm{SeO}_{3}$ is not caused by the change of transition metal salts, from $\mathrm{Na}_{2} \mathrm{MoO}_{4}$ to $\left(\mathrm{NH}_{4}\right)_{2} \mathrm{MoO}_{4}$. In controlled experiments, there is no $\mathrm{MoSe}_{2}$ observed when only $\left(\mathrm{NH}_{4}\right)_{2} \mathrm{MoO}_{4}$ is used (Figure S5a and $\mathrm{S} 5 \mathrm{~b}$ ).

Second, it is widely accepted that the $\mathrm{Na}^{+}$plays vital roles in the growth of TMDCs, which include liquefaction of metal oxides, promoting lateral growth and inducing chalcogen attachment. ${ }^{17,20,23,42-44}$ To validate the importance of $\mathrm{Na}^{+}$, the $\mathrm{MoSe}_{2}$ growth is conducted using salt precursors with/without $\mathrm{Na}^{+}$at fixed $\mathrm{SeO}_{3}{ }^{2-}$ and $\mathrm{MoO}_{4}{ }^{2-}$ molar ratio, i.e. $\left(\mathrm{NH}_{4}\right)_{2} \mathrm{MoO}_{4}-\mathrm{Na}_{2} \mathrm{SeO}_{3}(16 \mathrm{mM}, 1: 1)$ and $\left(\mathrm{NH}_{4}\right)_{2} \mathrm{MoO}_{4}-\mathrm{H}_{2} \mathrm{SeO}_{3}(16 \mathrm{mM}, 1: 1)$. Even with the presence of $\mathrm{SeO}_{3}{ }^{2-}$ in the mixed salts, changing the $\mathrm{Na}^{+}$to $\mathrm{H}^{+}$or reducing the $\mathrm{Na}^{+}$content leads to poor $\mathrm{MoSe}_{2}$ growth (Figure S5c-f and Figure S6). This further confirms the necessity of $\mathrm{Na}^{+}$ being an indispensable element for the growth of $\mathrm{MoSe}_{2} \cdot \mathrm{A} \mathrm{Na}^{+}: \mathrm{MoO}_{4}{ }^{2-}$ molar ratio higher than 2 is needed for the successful growth of continuous $\mathrm{MoSe}_{2}$ film. This is because the $\mathrm{Na}^{+}$works better than $\mathrm{NH}_{4}{ }^{+}$and $\mathrm{H}^{+}$in stabilizing $\mathrm{MoO}_{4}{ }^{2-}$ during the temperature ramping process. Since 
the use of $\mathrm{Na}_{2} \mathrm{MoO}_{4}$ only lead to an inferior growth, the results above suggest that both $\mathrm{Na}^{+}$ and $\mathrm{SeO}_{3}{ }^{2-}$ have a synergistic effect on the enhanced CVD growth of large-area wafer-scale $\mathrm{MoSe}_{2}$ film. The effect of different $\mathrm{Na}^{+}: \mathrm{SeO}_{3}{ }^{2-}: \mathrm{MoO}_{4}{ }^{2-}$ molar ratios on the CVD growth of $\mathrm{MoSe}_{2}$ is summarized in Figure 4f.
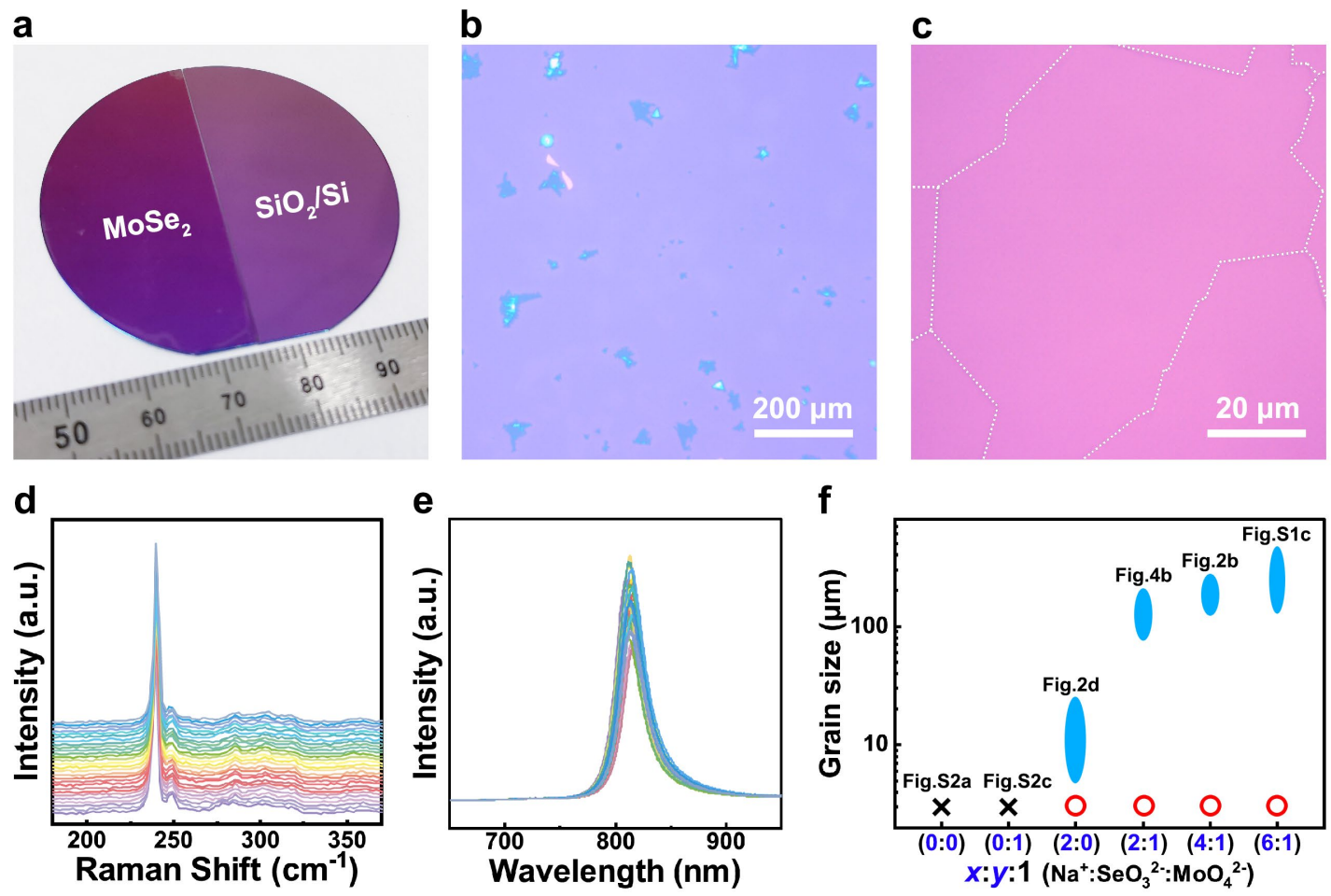

Figure 4. Contribution of $\mathrm{SeO}_{3}{ }^{2-}$ and $\mathrm{Na}^{+}$in the $\mathrm{MoSe}_{2}$ growth with mixed salts. (a) A photo of monolayer $\mathrm{MoSe}_{2}$ film grown on a halved 2-inch $\mathrm{SiO}_{2} / \mathrm{Si}$ wafer with $\left(\mathrm{NH}_{4}\right)_{2} \mathrm{MoO}_{4}$ $\mathrm{Na}_{2} \mathrm{SeO}_{3}$ (16mM, 1:1). (b, c) Optical images of monolayer $\mathrm{MoSe}_{2}$ film grown with $\left(\mathrm{NH}_{4}\right)_{2} \mathrm{MoO}_{4}-\mathrm{Na}_{2} \mathrm{SeO}_{3}(16 \mathrm{mM}, 1: 1)$. The dotted lines indicate the grain boundaries. (d) Raman and (e) PL spectra of the as-grown $\mathrm{MoSe}_{2}$ film. $\sim 30$ spectra were obtained from the monolayer $\mathrm{MoSe}_{2}$ film shown in (a). (f) The effect of different $\mathrm{Na}^{+}: \mathrm{SeO}_{3}{ }^{2-}: \mathrm{MoO}_{4}{ }^{2-}$ molar ratios on the CVD growth of $\mathrm{MoSe}_{2}$. 
Besides the above-mentioned reasons, we also notice that the addition of $\mathrm{Na}_{2} \mathrm{SeO}_{3}$ to $\mathrm{Na}_{2} \mathrm{MoO}_{4}$ results in more uniform precursor coating on $\mathrm{SiO}_{2} / \mathrm{Si}$ substrates, even after hightemperature annealing (typical CVD process without introducing Se) (Figure S7). This is particularly important as in our previous study on the $\mathrm{MoS}_{2}$ growth implied that monolayer films formed only on area covered with densely and uniformly distributed, small $\mathrm{Na}_{2} \mathrm{MoO}_{4}$ particles, whereas otherwise on area with low-density, large $\mathrm{Na}_{2} \mathrm{MoO}_{4}$ particles. ${ }^{18}$ Note that a high $\mathrm{Na}_{2} \mathrm{SeO}_{3}: \mathrm{Na}_{2} \mathrm{MoO}_{4}$ molar ratio of 2 will lead to the aggregation of mixed salt precursors, forming large particles. In this case, only isolated large monolayer $\mathrm{MoSe}_{2}$ flakes are grown (Figure S2c). Hence, careful tuning the molar ratio of the mixed salts is also an important key to the successful growth of continuous monolayer $\mathrm{MoSe}_{2}$ films (Figure 4f).

We further calculated the reaction energies for the possible reactions involved during $\mathrm{MoSe}_{2}$ and $\mathrm{WTe}_{2}$ growth by using the density functional theory (DFT) method. As shown in Table 1, for a typical growth of $\mathrm{MoSe}_{2}$ with $\mathrm{Na}_{2} \mathrm{MoO}_{4}$ only, the reaction energy is $-1.1 \mathrm{ev/f.u.,} \mathrm{Equation}$ (1-1). Increasing the $\mathrm{Na}_{2} \mathrm{SeO}_{3} / \mathrm{Na}_{2} \mathrm{MoO}_{4}$ ratios from 0.5 to 1 and 2, in Equations (1-2) to (1-3) and (1-4), results in a gradual decrease in the reaction energy from -1.96 to -3.00 and -4.93 ev/f.u., respectively. This implies that the addition of $\mathrm{Na}_{2} \mathrm{SeO}_{3}$ is thermodynamically favored for the growth of $\mathrm{MoSe}_{2}$. For the case of $\mathrm{WTe}_{2}$, a similar trend is observed. The introduction of $\mathrm{Na}_{2} \mathrm{TeO}_{3}$ results in a significantly lowered reaction energy from 2.06 ev/f.u. in Equation (21) to $-0.26 \mathrm{ev/f.u.} \mathrm{in} \mathrm{Equation(2-2).} \mathrm{These} \mathrm{results} \mathrm{are} \mathrm{in} \mathrm{consistent} \mathrm{to} \mathrm{our} \mathrm{experimental} \mathrm{findings,}$ where the initial poor/limited growth with only the transition metal salts used has improved with the chalcogen salts added, confirming the feasibility of this strategy to the growth of $2 \mathrm{D}$ $\mathrm{MoSe}_{2}$ and $\mathrm{WTe}_{2}$. 
Table 1. Possible chemical reactions and corresponding reaction energies for the growth of $\mathrm{MoSe}_{2}$ and $\mathrm{WTe}_{2}$

Reaction

Possible chemical reaction

energy

(eV/f.u.)

\begin{tabular}{clc}
\hline $1-1$ & $\mathrm{Na}_{2} \mathrm{MoO}_{4}+3 \mathrm{Se}+4 \mathrm{H}_{2}=\mathrm{MoSe}_{2}+\mathrm{Na}_{2} \mathrm{Se}+4 \mathrm{H}_{2} \mathrm{O}$ & -1.1 \\
$1-2$ & $\mathrm{Na}_{2} \mathrm{MoO}_{4}+0.5 \mathrm{Na}_{2} \mathrm{SeO}_{3}+3 \mathrm{Se}+5.5 \mathrm{H}_{2}=\mathrm{MoSe}_{2}+1.5 \mathrm{Na}_{2} \mathrm{Se}+5.5 \mathrm{H}_{2} \mathrm{O}$ & -1.96 \\
$1-3$ & $\mathrm{Na}_{2} \mathrm{MoO}_{4}+\mathrm{Na}_{2} \mathrm{SeO}_{3}+3 \mathrm{Se}+7 \mathrm{H}_{2}=\mathrm{MoSe}_{2}+2 \mathrm{Na}_{2} \mathrm{Se}+7 \mathrm{H}_{2} \mathrm{O}$ & -3.00 \\
$1-4$ & $\mathrm{Na}_{2} \mathrm{MoO}_{4}+2 \mathrm{Na}_{2} \mathrm{SeO}_{3}+3 \mathrm{Se}+10 \mathrm{H}_{2}=\mathrm{MoSe}_{2}+3 \mathrm{Na}_{2} \mathrm{Se}+10 \mathrm{H}_{2} \mathrm{O}$ & -4.93 \\
\hline $2-1$ & $\mathrm{Na}_{2} \mathrm{WO}_{4}+3 \mathrm{Te}+4 \mathrm{H}_{2}=\mathrm{WTe}_{2}+\mathrm{Na}_{2} \mathrm{Te}+4 \mathrm{H}_{2} \mathrm{O}$ & 2.06 \\
$2-2$ & $\mathrm{Na}_{2} \mathrm{WO}_{4}+2 \mathrm{Na}_{2} \mathrm{TeO}_{3}+3 \mathrm{Te}+10 \mathrm{H}_{2}=\mathrm{WTe}_{2}+3 \mathrm{Na}_{2} \mathrm{Te}+10 \mathrm{H}_{2} \mathrm{O}$ & -0.26 \\
\hline
\end{tabular}

\section{CONCLUSIONS}

In summary, we demonstrated an enhanced CVD growth of 2D TMD selenides and tellurides using mixed transition metal salts and chalcogen salts. The addition of $\mathrm{Na}_{2} \mathrm{SeO}_{3}$ to $\mathrm{Na}_{2} \mathrm{MoO}_{4}$ or $\left(\mathrm{NH}_{4}\right)_{2} \mathrm{MoO}_{4}$, induces a dramatic enhancement in the wafer-scale growth of $\mathrm{MoSe}_{2}$, forming continuous monolayer films with high reproducibility and uniformity at large gain size of 100-250 $\mu \mathrm{m}$. Similarly, high-efficiency growth of $\mathrm{WTe}_{2}$ is also achieved when mixed salts, $\mathrm{Na}_{2} \mathrm{WO}_{4}-\mathrm{Na}_{2} \mathrm{TeO}_{3}$ are used as growth precursors. This versatile strategy could also be a useful strategy for the growth of other 2D TMDCs and alloys with heterogeneous chalcogen species. 


\section{EXPERIMENTAL SECTION}

\section{Growth of 2D TMDCs.}

$\mathrm{MoSe}_{2}$. First, mixed $\mathrm{Na}_{2} \mathrm{MoO}_{4}-\mathrm{Na}_{2} \mathrm{SeO}_{3}$ solutions with molar ratios of 1:0.5, 1:1 and 1:2 were prepared, respectively. In the mixed salt solutions, the concentration of $\mathrm{Na}_{2} \mathrm{MoO}_{4}$ was kept $16 \mathrm{mM}$. Then, the mixed salt solutions were spin-coated onto $\mathrm{SiO}_{2} / \mathrm{Si}$ substrates with a speed of $8000 \mathrm{rpm}$ for $30 \mathrm{~s}$. The CVD growth was performed in a 2-inch tube furnace. The growth substrates were placed in the center of tube furnace, while a quartz crucible containing $\sim 500 \mathrm{mg}$ Se was placed in the upstream at $\sim 300{ }^{\circ} \mathrm{C}$ during the growth. $200 \mathrm{sccm} \mathrm{Ar} / \mathrm{H}_{2}(5 \%$ $\mathrm{H}_{2}$ ) forming gas was introduced as carrier gas. The optimal growth temperature window is 775 $850{ }^{\circ} \mathrm{C}$. After CVD growth for 5-10 mins, the tube furnace was cooled down to room temperature in $30 \mathrm{~min}$. To identify the functions of $\mathrm{Na}\left(\mathrm{Na}^{+}\right)$and $\mathrm{Se}\left(\mathrm{SeO}_{3}{ }^{2-}\right)$ in the enhanced CVD growth of $\mathrm{MoSe}_{2}$, we also preformed controlled CVD growths with $\mathrm{Na}_{2} \mathrm{MoO}_{4}$, $\left(\mathrm{NH}_{4}\right)_{2} \mathrm{MoO}_{4},\left(\mathrm{NH}_{4}\right)_{2} \mathrm{MoO}_{4}-\mathrm{Na}_{2} \mathrm{SeO}_{3}(1: 1)$ and $\left(\mathrm{NH}_{4}\right)_{2} \mathrm{MoO}_{4}-\mathrm{H}_{2} \mathrm{SeO}_{3}(1: 1)$, the $\mathrm{MoO}_{4}{ }^{2-}$ is 16 $\mathrm{mM}$ in all the aqueous solutions.

$\mathrm{ReSe}_{2}$. First, $20 \mathrm{mM}$ mixed $\mathrm{NaReO}_{4}-\mathrm{Na}_{2} \mathrm{SeO}_{3}$ (1:1) aqueous solution was prepared. The mixed salt deposition and CVD processes are similar to the growth of $\mathrm{MoSe}_{2}$. The optimal growth temperature for $\mathrm{ReSe}_{2}$ is $\sim 750^{\circ} \mathrm{C}$.

$W T e_{2}$. First, $20 \mathrm{mM}$ mixed $\mathrm{Na}_{2} \mathrm{WO}_{4}-\mathrm{Na}_{2} \mathrm{TeO}_{3}$ (1:1) aqueous solution was prepared. Then, the mixed salt solutions were spin-coated onto sapphire substrates with a speed of $5000 \mathrm{rpm}$ for $30 \mathrm{~s}$. The growth substrates were placed in the center of the 2-inch tube furnace with a new quartz tube. A quartz crucible containing $\sim 500 \mathrm{mg}$ Te was placed in the upstream at $\sim 550{ }^{\circ} \mathrm{C}$ during growth. $100 \mathrm{sccm} \mathrm{Ar} / \mathrm{H}_{2}\left(5 \% \mathrm{H}_{2}\right)$ forming gas was introduced as carrier gas. The optimal 
growth temperature window is $775-825^{\circ} \mathrm{C}$. After CVD growth for $5 \mathrm{mins}$, the tube furnace was cooled down to room temperature in $30 \mathrm{~min}$.

\section{Characterization of 2D TMDCs.}

Raman and $P L$. The micro-Raman/PL was performed using a laser confocal microscope (inVia, Renishaw). The 532-nm excitation laser was focused on the sample surface with a 100× objective lens. Then, Raman/PL signals from the TMDC samples were detected by an electron multiplying CCD detector (Andor) through a grating with 1800 grooves/mm for Raman and 300 grooves/mm for PL. The laser spot size was about $1 \mu \mathrm{m}$ in diameter. Raman and PL mapping were conducted on the large $\mathrm{MoSe}_{2}$ monolayers with a step of $0.5 \mu \mathrm{m}$.

AFM. The AFM observations were performed in tapping mode by Asylum MFP-3D origin. STEM. STEM images of $\mathrm{MoSe}_{2}$ monolayer were acquired by using JEOL 2100F microscope equipped with dodecaple correctors and the cold field emission gun operating at $60 \mathrm{kV}$. The probe current was about $25-30 \mathrm{pA}$. The convergence semiangle was $35 \mathrm{mrad}$ and the inner acquisition semiangle was $79 \mathrm{mrad}$.

\section{Device fabrication and test.}

Device fabrication. For the large $\mathrm{MoSe}_{2}$ monolayers transferred on heavily doped silicon substrates with 285-nm-thick $\mathrm{SiO}_{2}$ layer, a layer of photoresist (OFPR-800LB, TOK) was first spin-coated at a speed of $5000 \mathrm{rpm}$ for $30 \mathrm{~s}$. Then, the substrates were baked at $100{ }^{\circ} \mathrm{C}$ for 5 mins. A standard LED photolithography process was conducted to define the channel shape (protected by photoresist after development). After developing in NMD-3 (TOK) and rinse 
with DI water, the surrounding exposed $\mathrm{MoSe}_{2}$ monolayers were etched with oxygen plasma. Next, a second LED photolithography was conducted to define the electrode patterns. Tri-layer of $\mathrm{Cr} / \mathrm{Pd} / \mathrm{Au}(1 / 10 / 50 \mathrm{~nm})$ was deposited as contacts via e-beam deposition. The final $\mathrm{MoSe}_{2}-$ FETs have channel length of $\sim 5 \mu \mathrm{m}$ and with of $\sim 20 \mu \mathrm{m}$ (Figure S3). Similar fabrication process was also conducted on the transferred $\mathrm{ReSe}_{2}$ and $\mathrm{WTe}_{2}$ without the etching procedure. For $\mathrm{ReS}_{2}$ - and $\mathrm{WTe}_{2}$-FETs, bi-layer of $\mathrm{Cr} / \mathrm{Au}(1 / 50 \mathrm{~nm})$ were deposited as contacts.

Measurement of TMDC-based FETs. To test the transport properties of $\mathrm{MoSe}_{2}-\mathrm{FETs}$, the devices were loaded in a vacuum chamber with a pressure of $\sim 2 \times 10^{-3} \mathrm{~Pa}$. The backgate bias $\left(\mathrm{V}_{\mathrm{gs}}\right)$ was scanned forward from $-10 \mathrm{~V}$ to $50 \mathrm{~V}$ and backward from $50 \mathrm{~V}$ to $-10 \mathrm{~V}$ with a step of $1 \mathrm{~V}$, the source-drain bias $\left(\mathrm{V}_{\mathrm{ds}}\right)$ is $2 \mathrm{~V}$. For the transport curves plotted in Figure $2 \mathrm{j}$, the $\mathrm{y}$ axis was normalized to conductivity using the channel current and device dimensions. For the $\mathrm{WTe}_{2}$-FETs, the backgate bias $\left(\mathrm{V}_{\mathrm{gs}}\right)$ was scanned forward from $-30 \mathrm{~V}$ to $30 \mathrm{~V}$ and backward from $30 \mathrm{~V}$ to $-30 \mathrm{~V}$ with a step of $1 \mathrm{~V}$, the source-drain bias $\left(\mathrm{V}_{\mathrm{ds}}\right)$ is $1 \mathrm{~V}$.

\section{Density functional theory (DFT) calculation.}

The reaction energies were evaluated using the DFT method within the generalized gradient approximation of the Perdew, Burke, and Ernzernhof functional as implemented in the Vienna ab initio simulation package. ${ }^{45,46}$ Electron-ion interactions were described using projectoraugmented wave pseudopotentials. ${ }^{47}$ A plane-wave kinetic-energy cutoff of $600 \mathrm{eV}$ and a kspacing of $0.2 \AA^{-1}$ in reciprocal space were used to ensure that the energy converged to better than $1 \mathrm{meV} /$ atom. All of the crystal structures were obtained from the Materials Project database. $^{48}$ 


\section{ASSOCIATED CONTENT}

Supporting Information.

This material is available free of charge via the Internet at http://pubs.acs.org.

The Supporting Information include: (i) schematic illustration of mixed-salt CVD process, (ii) characterization of as-grown 2D MoSe 2 and $\mathrm{ReSe}_{2}$, (iii) characterization of $\mathrm{MoSe}_{2}$-FETs, (iv) calculated energy of chemicals.

\section{AUTHOR INFORMATION}

Corresponding Authors

S. Li: li.shisheng@,nims.go.jp

T. Taniguchi: taniguchi.takaaki@nims.go.jp

\section{ORCID}

Shisheng Li: 0000-0001-9301-5559

Yung-Chang Lin: 0000-0002-3968-7239

Jinhua Hong: 0000-0002-6406-1780

Bo Gao: 0000-0003-1183-656X

Hong En Lim: 0000-0003-0347-8897

Xu Yang: 0000-0001-8195-5850

Song Liu: 0000-0003-3390-7795

Yoshitaka Tateyama: 0000-0002-5532-6134

Yoshiki Sakuma: 0000-0001-68047217

Kazuhito Tsukagoshi: 0000-0001-9710-2692

Kazu Suenaga: 0000-0002-6107-1123

Takaaki Taniguchi: 0000-0002-8460-5431

Notes

The authors declare no competing financial interests. 


\section{ACKNOWLEDGMENT}

S.L. acknowledges the support from JSPS-KAKENHI (19K15399, 21K04839). T.T. acknowledges the support from JSPS-KAKENHI (17K19187). Y.-C.L. and K.S. acknowledge support from the JST-CREST (JPMJCR20B1, JPMJCR20B5, JPMJCR1993), JSPSKAKENHI (18K14119), JSPS A3 Foresight Program, and Kazato Research Encouragement Prize. Y.S. acknowledges the support from JSPS-KAKENHI (17H03241). H.E.L. acknowledges the support from JSPS-KAKENHI (19K15393, 21K14498). B.G. and Y.T. thank the support by MEXT as "Program for Promoting Researches on the Supercomputer Fugaku (Fugaku Battery \& Fuel Cell Project), Grant JPMXP1020200301, and the supercomputer at NIMS. S.L. acknowledges all staff members of the Nanofabrication Group at NIMS for their support.

\section{References}

1. Fiori, G.; Bonaccorso, F.; Iannaccone, G.; Palacios, T.; Neumaier, D.; Seabaugh, A.; Banerjee, S. K.; Colombo, L., Electronics Based on Two-Dimensional Materials. Nat. Nanotechnol. 2014, 9, 768-779.

2. Gong, C.; Zhang, Y.; Chen, W.; Chu, J.; Lei, T.; Pu, J.; Dai, L.; Wu, C.; Cheng, Y.; Zhai, T., Electronic and Optoelectronic Applications Based on 2D Novel Anisotropic Yransition Metal Dichalcogenides. Adv. Sci. 2017, 4, 1700231.

3. Su, S.-K.; Chuu, C.-P.; Li, M.-Y.; Cheng, C.-C.; Wong, H.-S. P.; Li, L.-J., Layered Semiconducting 2D Materials for Future Transistor Applications. Small Structures, 2021, 2, 2000103.

4. Shi, J.; Huan, Y.; Zhao, X.; Yang, P.; Hong, M.; Xie, C.; Pennycook, S.; Zhang, Y., TwoDimensional Metallic Vanadium Ditelluride as a High-Performance Electrode Material. ACS Nano 2021, 15, 1858-1868.

5. Zhang, Z.; Gong, Y.; Zou, X.; Liu, P.; Yang, P.; Shi, J.; Zhao, L.; Zhang, Q.; Gu, L.; Zhang, Y., Epitaxial Growth of Two-Dimensional Metal-Semiconductor Transition-Metal 
Dichalcogenide Vertical Stacks $\left(\mathrm{VSe}_{2} / \mathrm{MX}_{2}\right)$ and Their Band Alignments. ACS Nano 2018, 13, 885-893.

6. Mleczko, M. J.; Xu, R. L.; Okabe, K.; Kuo, H.-H.; Fisher, I. R.; Wong, H.-S. P.; Nishi, Y.; Pop, E., High Current Density and Low Thermal Conductivity of Atomically Thin Semimetallic $\mathrm{WTe}_{2}$. ACS Nano 2016, 10, 7507-7514.

7. Lee, C.-S.; Oh, S. J.; Heo, H.; Seo, S.-Y.; Kim, J.; Kim, Y. H.; Kim, D.; Ngome Okello, O. F.; Shin, H.; Sung, J. H., Epitaxial van der Waals Contacts Between Transition-Metal Dichalcogenide Monolayer Polymorphs. Nano Lett. 2019, 19, 1814-1820.

8. Tan, J.; Li, S.; Liu, B.; Cheng, H.-M., Structure, Preparation, and Applications of 2D Material-Based Metal-Semiconductor Heterostructures. Small Structures 2021, 2, 2000093.

9. Kang, K.; Xie, S.; Huang, L.; Han, Y.; Huang, P. Y.; Mak, K. F.; Kim, C.-J.; Muller, D.; Park, J., High-Mobility Three-Atom-Thick Semiconducting Films with Wafer-Scale Homogeneity. Nature 2015, 520, 656-660.

10. Wang, D.; Luo, F.; Lu, M.; Xie, X.; Huang, L.; Huang, W., Chemical Vapor Transport Reactions for Synthesizing Layered Materials and Their 2D Counterparts. Small 2019, 15, 1804404.

11. Lee, Y. H.; Zhang, X. Q.; Zhang, W.; Chang, M. T.; Lin, C. T.; Chang, K. D.; Yu, Y. C.; Wang, J. T. W.; Chang, C. S.; Li, L. J., Synthesis of Large-Area $\mathrm{MoS}_{2}$ Atomic Layers with Chemical Vapor Deposition. Adv. Mater. 2012, 24, 2320-2325.

12. Shi, Y.; Li, H.; Li, L.-J., Recent Advances in Controlled Synthesis of Two-Dimensional Transition Metal Dichalcogenides via Vapour Deposition Techniques. Chem. Soc. Rev. 2015, 44, 2744-2756.

13. Huang, J.-K.; Pu, J.; Hsu, C.-L.; Chiu, M.-H.; Juang, Z.-Y.; Chang, Y.-H.; Chang, W.-H.; Iwasa, Y.; Takenobu, T.; Li, L.-J., Large-Area Synthesis of Highly Crystalline WSe 2 Monolayers and Device Applications. ACS Nano 2014, 8, 923-930.

14. Li, S.; Wang, S.; Tang, D.-M.; Zhao, W.; Xu, H.; Chu, L.; Bando, Y.; Golberg, D.; Eda, G., Halide-Assisted Atmospheric Pressure Growth of Large $\mathrm{WSe}_{2}$ and $\mathrm{WS}_{2}$ Monolayer Crystals. Appl. Mater. Today 2015, 1, 60-66. 
15. Zhou, J.; Lin, J.; Huang, X.; Zhou, Y.; Chen, Y.; Xia, J.; Wang, H.; Xie, Y.; Yu, H.; Lei, J., A Library of Atomically Thin Metal Chalcogenides. Nature 2018, 556, 355-359.

16. Liu, C.; Xu, X.; Qiu, L.; Wu, M.; Qiao, R.; Wang, L.; Wang, J.; Niu, J.; Liang, J.; Zhou, X., Kinetic Modulation of Graphene Growth by Fluorine Through Spatially Confined Decomposition of Metal Fluorides. Nat. Chem. 2019, 11, 730-736.

17. Li, S.; Lin, Y.-C.; Zhao, W.; Wu, J.; Wang, Z.; Hu, Z.; Shen, Y.; Tang, D.-M.; Wang, J.; Zhang, Q., Vapour-Liquid-Solid Growth of Monolayer $\mathrm{MoS}_{2}$ Nanoribbons. Nat. Mater. 2018, $17,535-542$.

18. Li, S.; Lin, Y.-C.; Liu, X.-Y.; Hu, Z.; Wu, J.; Nakajima, H.; Liu, S.; Okazaki, T.; Chen, W.; Minari, T., Wafer-Scale and Deterministic Patterned Growth of Monolayer $\mathrm{MoS}_{2}$ via VaporLiquid-Solid Method. Nanoscale 2019, 11, 16122-16129.

19. Liu, H.; Qi, G.; Tang, C.; Chen, M.; Chen, Y.; Shu, Z.; Xiang, H.; Jin, Y.; Wang, S.; Li, H., Growth of Large-Area Homogeneous Monolayer Transition-Metal Disulfides via a Molten Liquid Intermediate Process. ACS Appl. Mater. \& Interfaces 2020, 12, 13174-13181.

20. Chang, M.-C.; Ho, P.-H.; Tseng, M.-F.; Lin, F.-Y.; Hou, C.-H.; Lin, I.-K.; Wang, H.; Huang, P.-P.; Chiang, C.-H.; Yang, Y.-C., Fast Growth of Large-Grain and Continuous $\mathrm{MoS}_{2}$ Films Through a Self-Capping Vapor-Liquid-Solid Method. Nat. Commun. 2020, 11, 3682.

21. Zuo, Y.; Yu, W.; Liu, C.; Cheng, X.; Qiao, R.; Liang, J.; Zhou, X.; Wang, J.; Wu, M.; Zhao, Y., Optical Fibres with Embedded Two-Dimensional Materials for Ultrahigh Nonlinearity. Nat. Nanotechnol. 2020, 15, 987-991.

22. Li, S.; Hong, J.; Gao, B.; Lin, Y. C.; Lim, H. E.; Lu, X.; Wu, J.; Liu, S.; Tateyama, Y.; Sakuma, Y., Tunable Doping of Rhenium and Vanadium into Transition Metal Dichalcogenides for Two-Dimensional Electronics. Adv. Sci. 2021, 8, 2004438.

23. Cai, Z.; Lai, Y.; Zhao, S.; Zhang, R.; Tan, J.; Feng, S.; Zou, J.; Tang, L.; Lin, J.; Liu, B., Dissolution-Precipitation Growth of Uniform and Clean Two Dimensional Transition Metal Dichalcogenides. Nat. Sci. Rev. 2021, 8, nwaa115.

24. Gong, Y.; Lin, Z.; Ye, G.; Shi, G.; Feng, S.; Lei, Y.; Elias, A. L.; Perea-Lopez, N.; Vajtai, R.; Terrones, H., Tellurium-Assisted Low-Temperature Synthesis of $\mathrm{MoS}_{2}$ and $\mathrm{WS}_{2}$ Monolayers. ACS Nano 2015, 9, 11658-11666. 
25. Cui, F.; Wang, C.; Li, X.; Wang, G.; Liu, K.; Yang, Z.; Feng, Q.; Liang, X.; Zhang, Z.; Liu, S., Tellurium-Assisted Epitaxial Growth of Large-area, Highly Crystalline $\mathrm{ReS}_{2}$ Atomic Layers on Mica Substrate. Adv. Mater. 2016, 28, 5019-5024.

26. Tonndorf, P.; Schmidt, R.; Böttger, P.; Zhang, X.; Börner, J.; Liebig, A.; Albrecht, M.; Kloc, C.; Gordan, O.; Zahn, D. R., Photoluminescence Emission and Raman Response of Monolayer $\mathrm{MoS}_{2}, \mathrm{MoSe}_{2}$, and $\mathrm{WSe}_{2}$. Opt. Express 2013, 21, 4908-4916.

27. Liu, Z.; Amani, M.; Najmaei, S.; Xu, Q.; Zou, X.; Zhou, W.; Yu, T.; Qiu, C.; Birdwell, A. G.; Crowne, F. J., Strain and Structure Heterogeneity in $\mathrm{MoS}_{2}$ Atomic Layers Grown by Chemical Vapour Deposition. Nat. Commun. 2014, 5, 5246.

28. Yang, S.; Chen, Y.; Jiang, C., Strain Engineering of Two-Dimensional Materials: Methods, Properties, and Applications. InfoMat 2021, 3, 397-420.

29. Wang, X.; Gong, Y.; Shi, G.; Chow, W. L.; Keyshar, K.; Ye, G.; Vajtai, R.; Lou, J.; Liu, Z.; Ringe, E., Chemical Vapor Deposition Growth of Crystalline Monolayer MoSe2. ACS Nano 2014, $8,5125-5131$.

30. Han, H.-V.; Lu, A.-Y.; Lu, L.-S.; Huang, J.-K.; Li, H.; Hsu, C.-L.; Lin, Y.-C.; Chiu, M.H.; Suenaga, K.; Chu, C.-W., Photoluminescence Enhancement and Structure Repairing of Monolayer $\mathrm{MoSe}_{2}$ by Hydrohalic Acid Treatment. ACS Nano 2016, 10, 1454-1461.

31. Chen, M.-W.; Ovchinnikov, D.; Lazar, S.; Pizzochero, M.; Whitwick, M. B.; Surrente, A.; Baranowski, M.; Sanchez, O. L.; Gillet, P.; Plochocka, P., Highly Oriented Atomically Thin Ambipolar $\mathrm{MoSe}_{2}$ Grown by Molecular Beam Epitaxy. ACS Nano 2017, 11, 6355-6361.

32. Meng, Y.; Ling, C.; Xin, R.; Wang, P.; Song, Y.; Bu, H.; Gao, S.; Wang, X.; Song, F.; Wang, J., Repairing Atomic Vacancies in Single-Layer $\mathrm{MoSe}_{2}$ Field-Effect Transistor and Its Defect Dynamics. npj Quantum Mater. 2017, 2, 16.

33. Li, Y.; Zhang, K.; Wang, F.; Feng, Y.; Li, Y.; Han, Y.; Tang, D.; Zhang, B., Scalable Synthesis of Highly Crystalline $\mathrm{MoSe}_{2}$ and Its Ambipolar Behavior. ACS Appl. Mater. \& Interfaces 2017, 9, 36009-36016.

34. Chen, X.; Hu, P.; Song, K.; Wang, X.; Zuo, C.; Yang, R.; Wang, J., CVD Growth of LargeScale Hexagon-Like Shaped $\mathrm{MoSe}_{2}$ Monolayers with Sawtooth Edge. Chem. Phys. Lett. 2019, $733,136663$. 
35. Somvanshi, D.; Ber, E.; Bailey, C. S.; Pop, E.; Yalon, E., Improved Current Density and Contact Resistance in Bilayer $\mathrm{MoSe}_{2}$ Field Effect Transistors by $\mathrm{AlO}_{\mathrm{x}}$ Capping. ACS Appl. Mater. \& Interfaces 2020, 12, 36355-36361.

36. Kim, M.; Seo, J.; Kim, J.; Moon, J. S.; Lee, J.; Kim, J.-H.; Kang, J.; Park, H., HighCrystalline Monolayer Transition Metal Dichalcogenides Films for Wafer-Scale Electronics. ACS Nano 2021, 15, 3038-3046.

37. Chen, Z.; Liu, H.; Chen, X.; Chu, G.; Chu, S.; Zhang, H., Wafer-Size and Single-Crystal $\mathrm{MoSe}_{2}$ Atomically Thin Films Grown on GaN Dubstrate for Light Emission and Harvesting. ACS Appl. Mater. Interfaces 2016, 8, 20267-20273.

38. Li, J.; Yan, W.; Lv, Y.; Leng, J.; Zhang, D.; Coileáin, C. Ó.; Cullen, C. P.; Stimpel-Lindner, T.; Duesberg, G. S.; Cho, J., Sub-Millimeter Size High Mobility Single Crystal MoSe 2 Monolayers Synthesized by NaCl-Assisted Chemical Vapor Deposition. RSC Adv. 2020, 10, $1580-1587$.

39. Li, N.; Wang, Q.; Shen, C.; Wei, Z.; Yu, H.; Zhao, J.; Lu, X.; Wang, G.; He, C.; Xie, L., Large-Scale Flexible and Transparent Electronics Based on Monolayer Molybdenum Disulfide Field-Effect Transistors. Nat. Electron. 2020, 3, 711-717.

40. Zhou, Z.; Xu, T.; Zhang, C.; Li, S.; Xu, J.; Sun, L.; Gao, L., Enhancing Stability by Tuning Element Ratio in 2D Transition Metal Chalcogenides. Nano Res. 2021, 14, 1704-1710.

41. Li, J.; Cheng, S.; Liu, Z.; Zhang, W.; Chang, H., Centimeter-Scale, Large-Area, Few-Layer $1 \mathrm{~T}^{\prime}-\mathrm{WTe}_{2}$ Films by Chemical Vapor Deposition and Its Long-Term Stability in Ambient Condition. J. Phys. Chem. C 2018, 122, 7005-7012.

42. Yang, P.; Zou, X.; Zhang, Z.; Hong, M.; Shi, J.; Chen, S.; Shu, J.; Zhao, L.; Jiang, S.; Zhou, X., Batch Production of 6-Inch Uniform Monolayer Molybdenum Disulfide Catalyzed by Sodium in Glass. Nat. Commun. 2018, 9, 979.

43. Xie, C.; Yang, P.; Huan, Y.; Cui, F.; Zhang, Y., Roles of Salts in the Chemical Vapor Deposition Synthesis of Two-Dimensional Transition Metal Chalcogenides. Dalton Trans. 2020, 49, 10319-10327. 
44. Kim, H.; Ovchinnikov, D.; Deiana, D.; Unuchek, D.; Kis, A., Suppressing Nucleation in Metal-Organic Chemical Vapor Deposition of $\mathrm{MoS}_{2}$ Monolayers by Alkali Metal Halides. Nano Lett. 2017, 17, 5056-5063.

45. Perdew, J. P.; Burke, K.; Ernzerhof, M., Generalized gradient approximation made simple. Phys. Rev. Lett. 1996, 77, 3865.

46. Kresse, G.; Joubert, D., From ultrasoft pseudopotentials to the projector augmented-wave method. Phy. Rev. B 1999, 59, 1758.

47. Blöchl, P. E., Projector augmented-wave method. Phy. Rev. B 1994, 50, 17953.

48. Jain, A.; Ong, S. P.; Hautier, G.; Chen, W.; Richards, W. D.; Dacek, S.; Cholia, S.; Gunter, D.; Skinner, D.; Ceder, G., Commentary: The Materials Project: A materials genome approach to accelerating materials innovation. APL Mater. 2013, 1, 011002. 


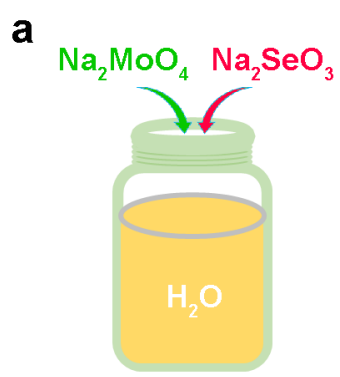

Liquid precursor b

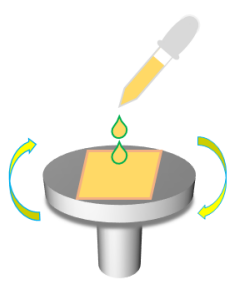

Spin-coating
C

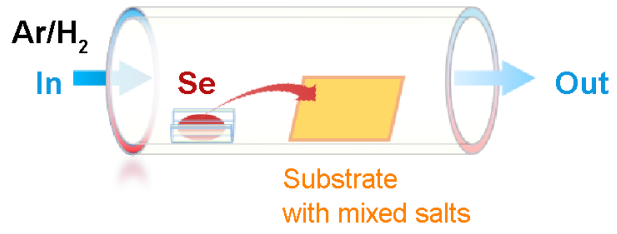

CVD (selenization)

Figure S1. Schematic illustrations of the enhanced CVD growth of monolayer $\mathrm{MoSe}_{2}$ films using mixed $\mathrm{Na}_{2} \mathrm{MoO}_{4} / \mathrm{Na}_{2} \mathrm{SeO}_{3}$. (a) The preparation of liquid precursors by dissolving $\mathrm{Na}_{2} \mathrm{MoO}_{4}$ and $\mathrm{Na}_{2} \mathrm{SeO}_{3}$ in $\mathrm{DI} \mathrm{H}_{2} \mathrm{O}$. (b) Depositing mixed salts on growth substrate via spincoating of the liquid precursor. (c) CVD growth of $\mathrm{MoSe}_{2}$ films via selenization of the mixed $\mathrm{Na}_{2} \mathrm{MoO}_{4} / \mathrm{Na}_{2} \mathrm{SeO}_{3}$ on substrate. 
$\mathrm{Na}_{2} \mathrm{MoO}_{4}: \mathrm{Na}_{2} \mathrm{SeO}_{3}$ molar ratio

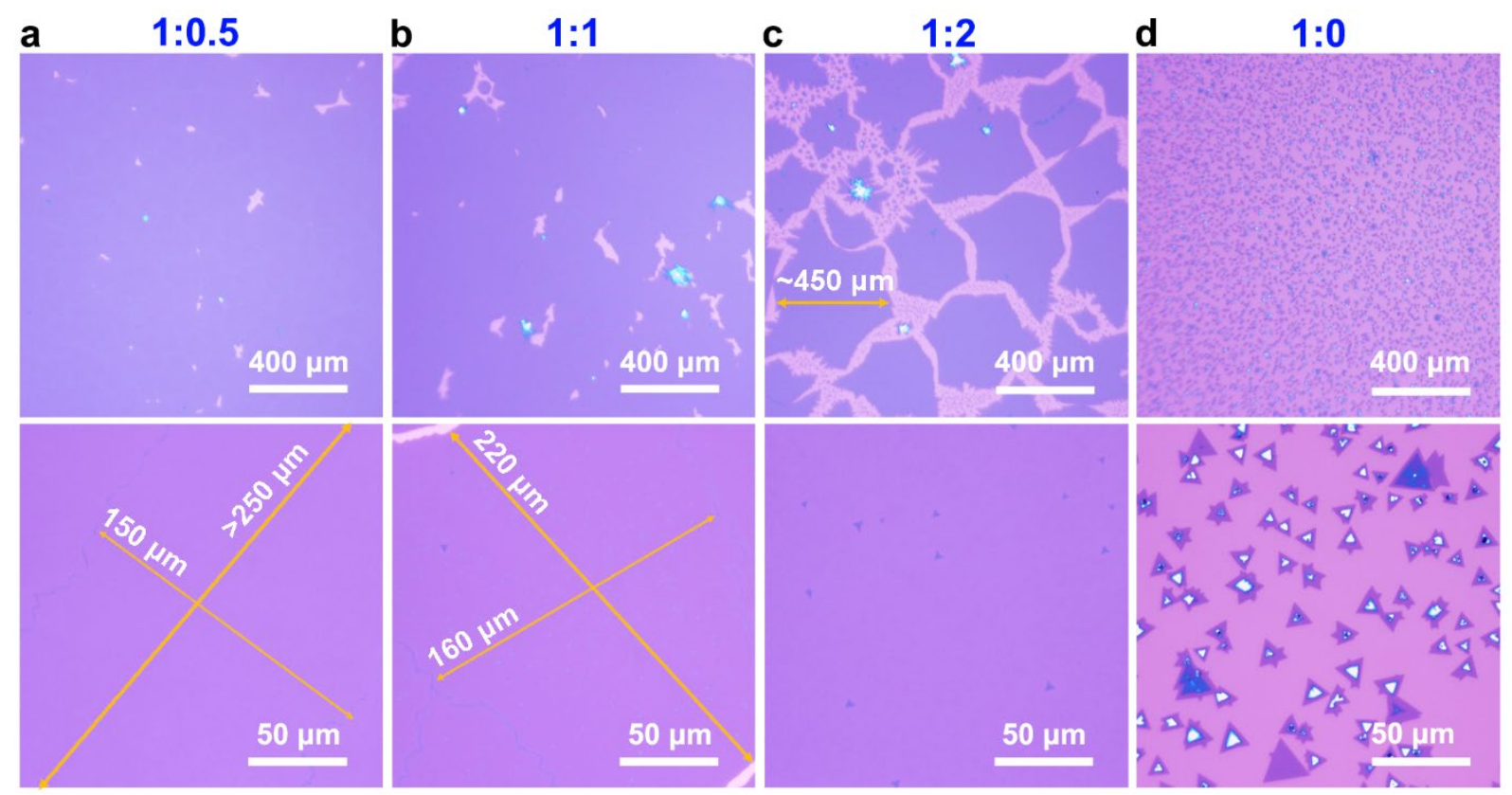

Figure S2. Optical images of $\mathrm{MoSe}_{2}$ grown on $\mathrm{SiO}_{2} / \mathrm{Si}$ substrates with different $\mathrm{Na}_{2} \mathrm{MoO}_{4}: \mathrm{Na}_{2} \mathrm{SeO}_{3}$ ratios. (a) 1:0.5, (b) 1:1, (c) 1:2 and (d) 1:0. Large $\mathrm{MoSe}_{2}$ monolayers with grain size in the range of $150-450 \mu \mathrm{m}$ can be grown when using mixed $\mathrm{Na}_{2} \mathrm{MoO}_{4}-\mathrm{Na}_{2} \mathrm{SeO}_{3}$ as growth precursors. 

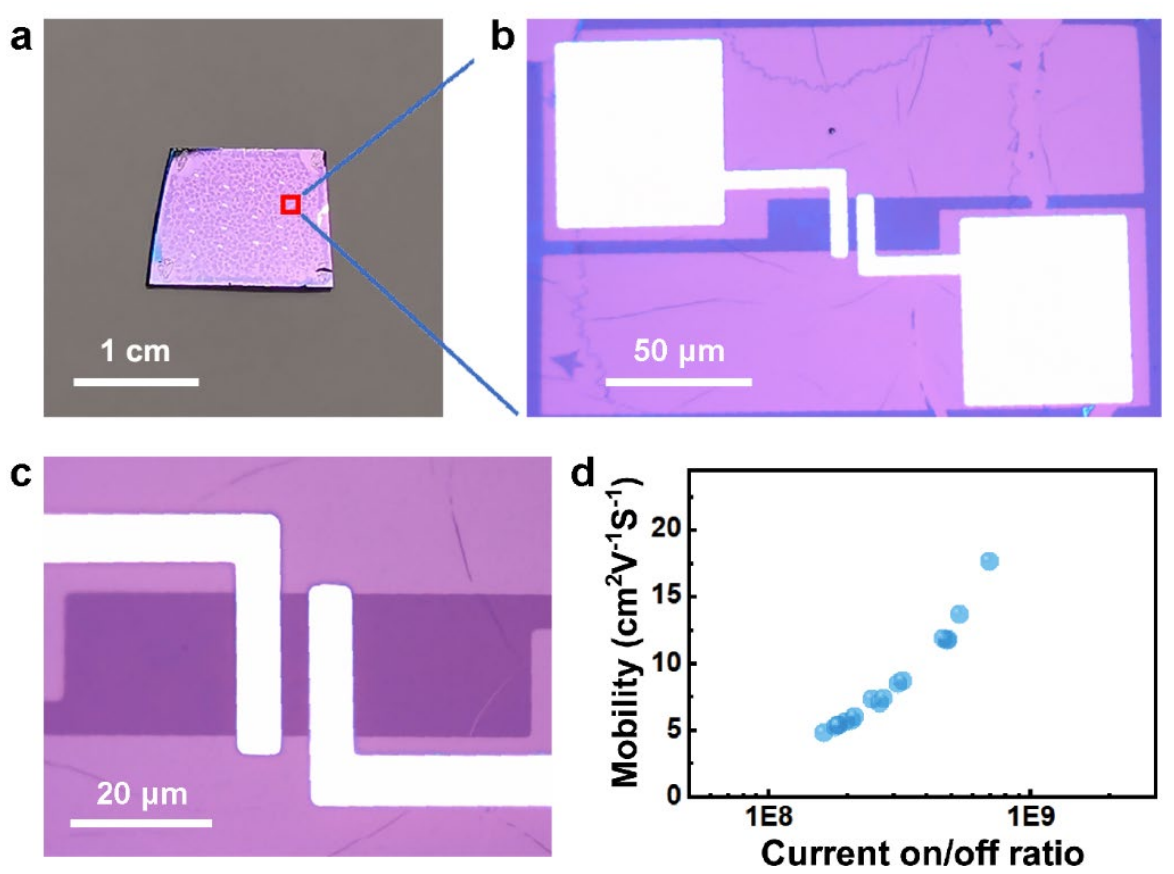

Figure S3. Monolayer MoSe $\mathbf{S}_{2}$-FETs. (a) An array of monolayer $\mathrm{MoSe}_{2}$-FETs fabricated with $\mathrm{MoSe}_{2}$ film transferred on $285 \mathrm{~nm} \mathrm{SiO} 2(285 \mathrm{~nm}) / \mathrm{Si}$ substrate $\left(\sim 10 \times 10 \mathrm{~mm}^{2}\right)$. (b, c) Optical images of a single $\mathrm{MoSe}_{2}$-FET. Photolithography and oxygen plasma were employed to define the channel shape and etch surrounding $\mathrm{MoSe}_{2}$. (d) Statistical result of the electron mobility vs. current on/off ratio for a total of $16 \mathrm{MoSe}_{2}$-FETs measured. 

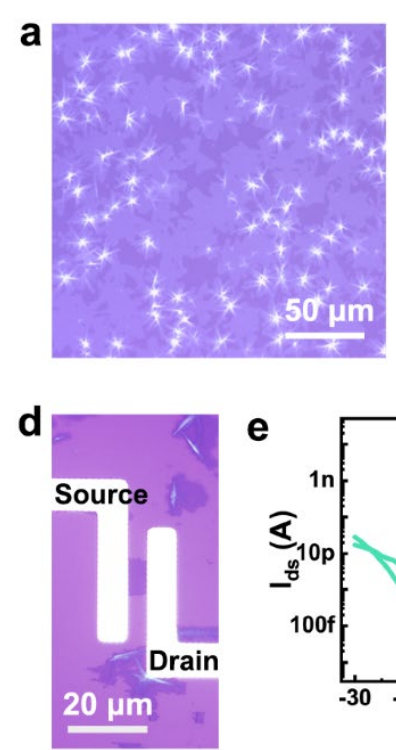

b
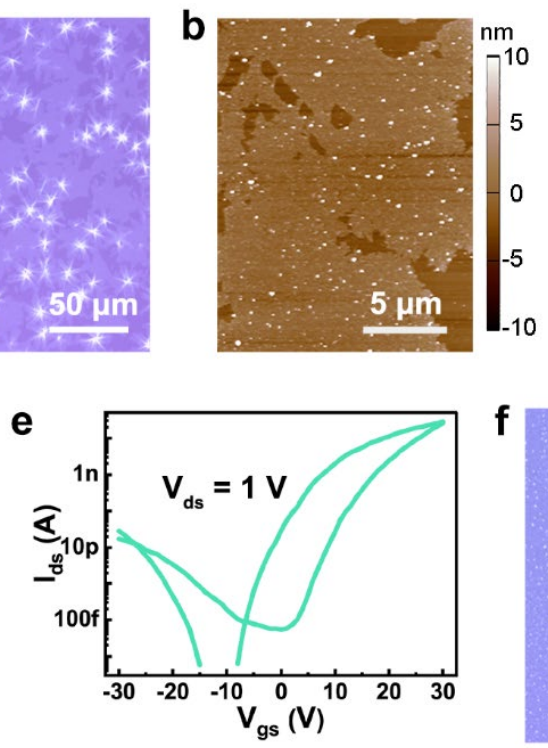

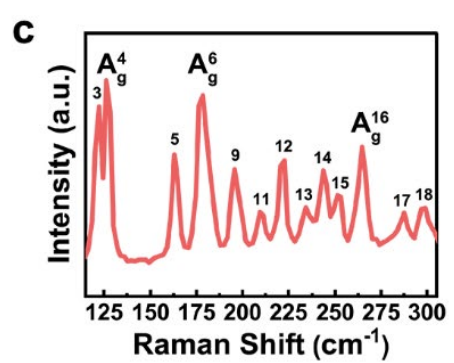

$\mathbf{f}$

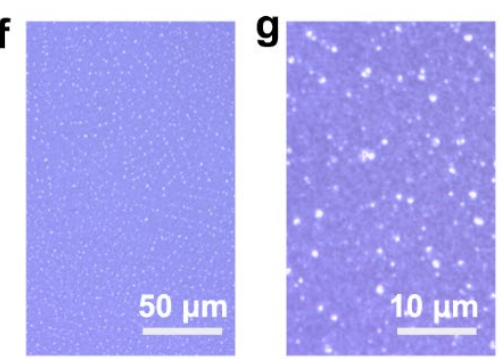

Figure S4. Characterization of $\mathrm{ReSe}_{2}$ grown with mixed $\mathrm{NaReO}_{4}-\mathrm{Na}_{2} \mathrm{SeO}_{3}$. (a) An optical image showing the as-grown $\mathrm{ReSe}_{2}$ flakes on sapphire substrate. (b) An AFM image of the $\mathrm{ReSe}_{2}$ flakes transferred onto a $\mathrm{SiO}_{2} / \mathrm{Si}$ substrate. (c) Typical Raman spectrum of the as-grown $\operatorname{ReSe}_{2}$ flakes. (d, e) Typical (d) optical image and (e) transport curve of a $\operatorname{ReSe}_{2}$-FET. (f, g) Optical images of as-grown small $\mathrm{ReSe}_{2}$ flakes using $\mathrm{NaReO}_{4}$ only. 
a

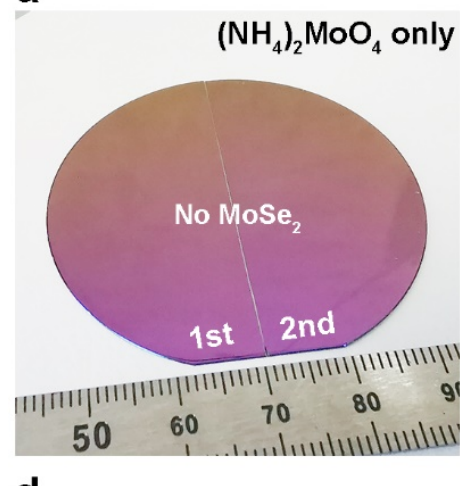

d

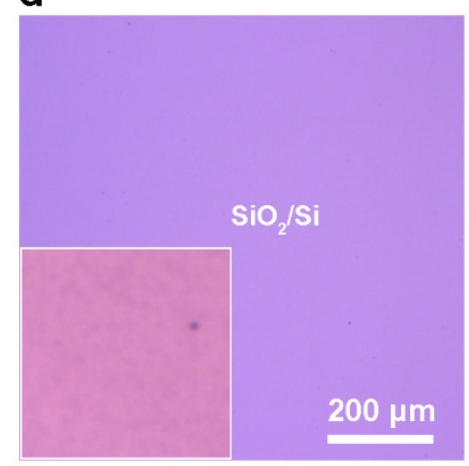

b

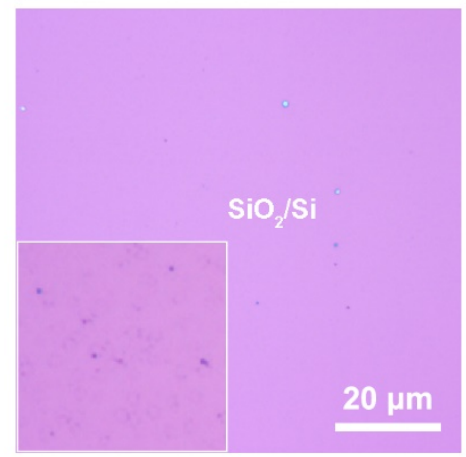

e

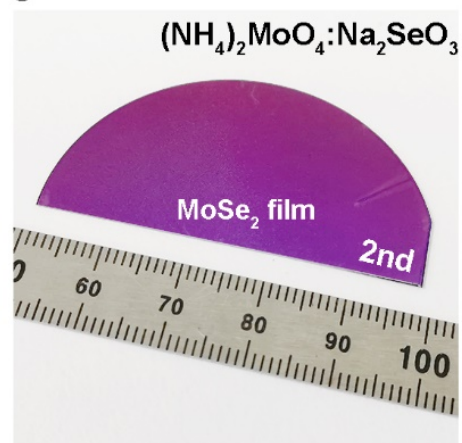

C

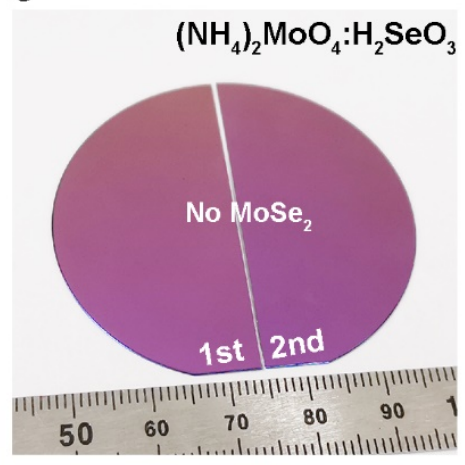

f

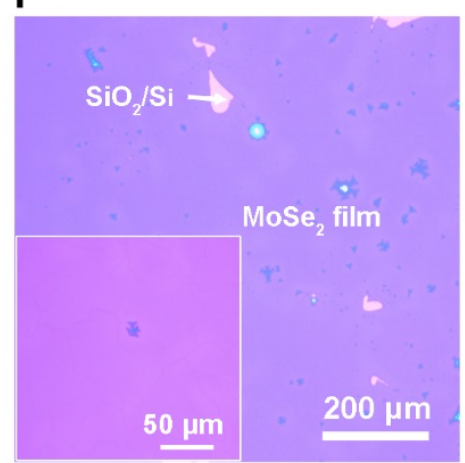

Figure S5. Controlled experiments using different salt precursors. (a, b) A photo and optical images show the repeated growth of $\mathrm{MoSe}_{2}$ with $\left(\mathrm{NH}_{4}\right)_{2} \mathrm{MoO}_{4}$ only $\left(\mathrm{No} \mathrm{Na}^{+}\right.$and $\left.\mathrm{SeO}_{3}{ }^{2-}\right)$, and there is no $\mathrm{MoSe}_{2}$ was observed after the CVD growth. Inset shows an area of $10 \times 10 \mu \mathrm{m}^{2}$. (c, d) A photo and optical images show the repeated growth of $\mathrm{MoSe}_{2}$ with $(\mathrm{NH} 4)_{2} \mathrm{MoO}_{4}-$ $\mathrm{H}_{2} \mathrm{SeO}_{3}\left(\mathrm{No} \mathrm{Na}^{+}\right)$, and there is no $\mathrm{MoSe}_{2}$ was able to grow the mixed salts. Inset shows an area of $10 \times 10 \mu \mathrm{m}^{2}$. (e, f) A photo and optical images show the second growth of monolayer $\mathrm{MoSe}_{2}$ film with $\left(\mathrm{NH}_{4}\right)_{2} \mathrm{MoO}_{4}-\mathrm{Na}_{2} \mathrm{SeO}_{3}(16 \mathrm{mM}, 1: 1)$ on a half of 2-inch $\mathrm{SiO}_{2} / \mathrm{Si}$ wafer, and (f) optical images show the morphology of as-grown monolayer $\mathrm{MoSe}_{2}$ film. 


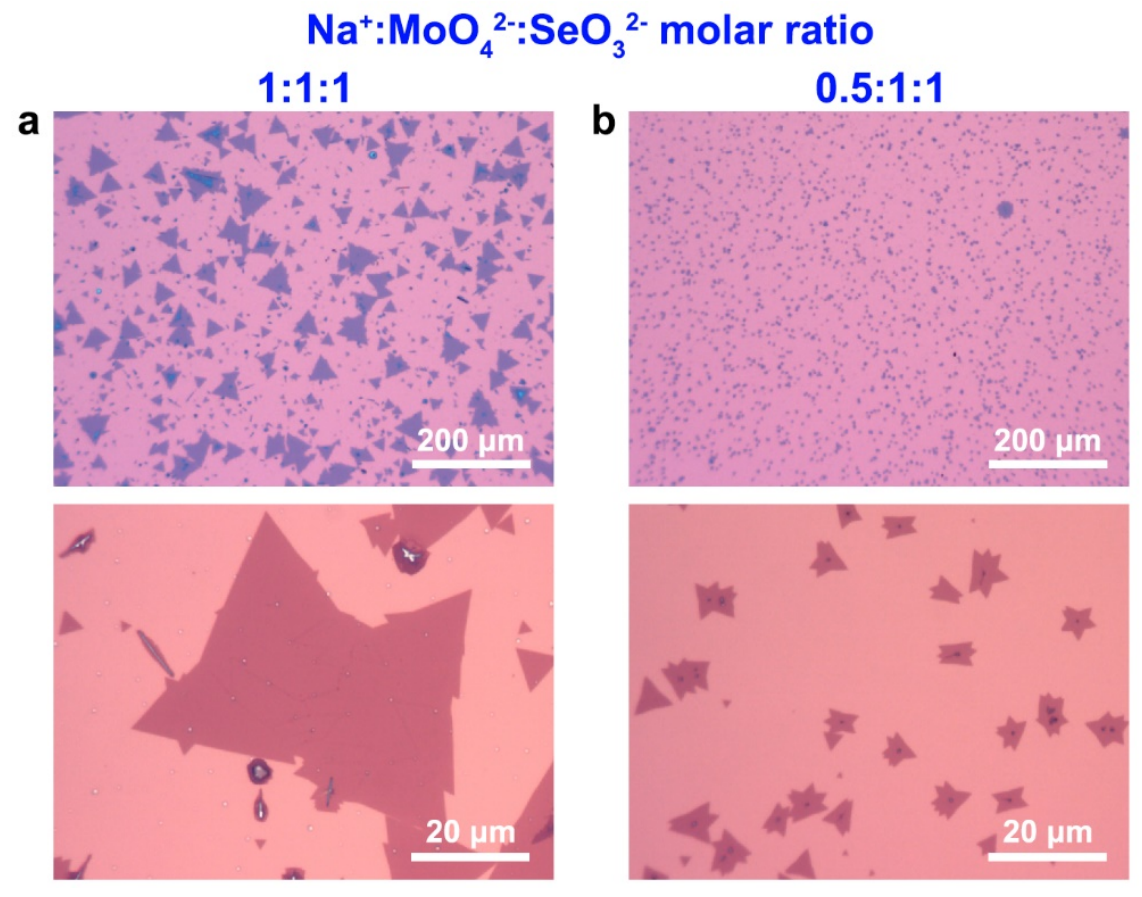

Figure S6. Controlled experiments using different $\mathbf{N a}^{+}$contents. Optical images of $\mathrm{MoSe}_{2}$ monolayers grown with $\mathrm{Na}^{+}: \mathrm{MoO}_{4}{ }^{2-}: \mathrm{SeO}_{3}{ }^{2-}$ molar ratios of (a) $1: 1: 1$ and (b) $0.5: 1: 1$. The molar concentration of $\mathrm{MoO}_{4}{ }^{2-}$ and $\mathrm{SeO}_{3}{ }^{2-}$ is $16 \mathrm{mM}$, prepared using a mixture of $\mathrm{Na}_{2} \mathrm{MoO}_{4}$, $\left(\mathrm{NH}_{4}\right)_{2} \mathrm{MoO}_{4}$ and $\mathrm{H}_{2} \mathrm{SeO}_{3}$. 


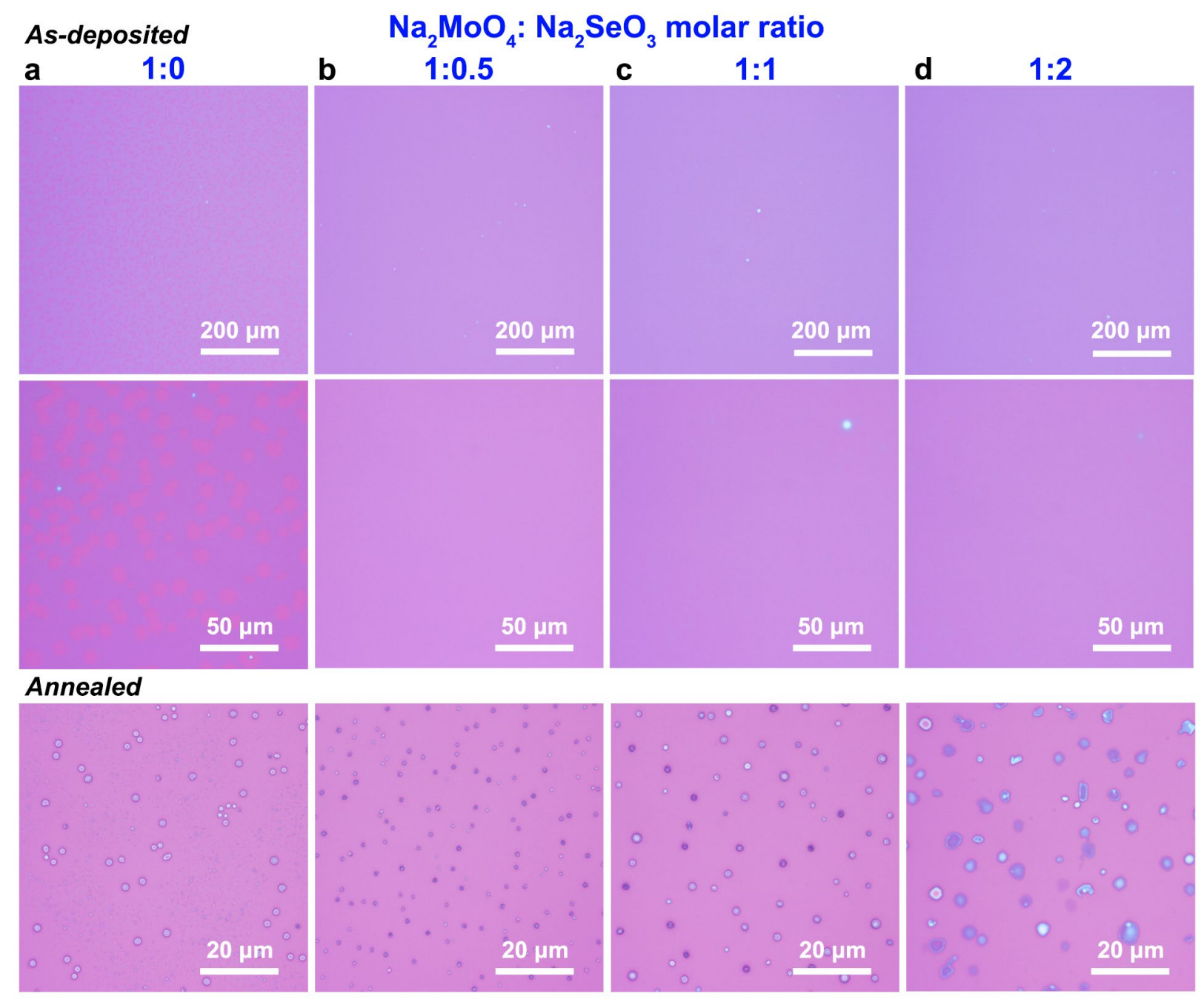

Figure S7. Comparison of spin-coated mixed-salt precursors with different $\mathrm{Na}_{2} \mathrm{MoO}_{4}: \mathrm{Na}_{2} \mathrm{SeO}_{3}$ molar ratios. The $\mathrm{Na}_{2} \mathrm{MoO}_{4}: \mathrm{Na}_{2} \mathrm{SeO}_{3}$ molar ratios are (a) 1:0; (b) 1:0.5; (c) $1: 1$ and (d) 1:2. In all salt precursors, the $\mathrm{Na}_{2} \mathrm{MoO}_{4}$ is kept as $16 \mathrm{mM}$. The spin-coating condition is $8000 \mathrm{rpm}$ for $30 \mathrm{~s}$. The first two rows show the morphologies of as-prepared salt precursors on $\mathrm{SiO}_{2} / \mathrm{Si}$ substrates. The third row shows the size and area-density of salt precursors after annealing in a typical CVD process without introducing selenium. 
Table S1. Calculated energy of chemicals

\begin{tabular}{|c|c|c|c|}
\hline & Energy (eV/f.u.) & & Energy (eV/f.u.) \\
\hline $\mathrm{MoSe}_{2}$ & -19.973 & $\mathrm{WTe}_{2}$ & -19.575 \\
\hline $\mathrm{Na}_{2} \mathrm{MoO}_{4}$ & -47.597 & $\mathrm{Na}_{2} \mathrm{WO}_{4}$ & -50.638 \\
\hline $\mathrm{Na}_{2} \mathrm{SeO}_{3}$ & -29.870 & $\mathrm{Na}_{2} \mathrm{TeO}_{3}$ & -29.831 \\
\hline $\mathrm{Na}_{2} \mathrm{Se}$ & -9.387 & $\mathrm{Na}_{2} \mathrm{Te}$ & -8.607 \\
\hline $\mathrm{Se}$ & -3.506 & $\mathrm{Te}$ & -3.142 \\
\hline $\mathrm{H}_{2}$ & -6.773 & $\mathrm{H} 2 \mathrm{O}$ & -14.229 \\
\hline
\end{tabular}

